\title{
Investigation on the Movement and Fracture Characteristics of an Extra-Thick Hard Roof during Longwall Panel Extraction in the Yima Mining Area, China
}

\author{
Hongwei Wang $\mathbb{D}^{1,2}$ Daixin Deng, ${ }^{1}$ Ruiming Shi, ${ }^{1}$ Guozhen Yang, ${ }^{1}$ Shuo Xu, ${ }^{1}$ \\ and Yaodong Jiang ${ }^{1,2}$ \\ ${ }^{1}$ School of Mechanics and Civil Engineering, China University of Mining and Technology, Beijing 100083, China \\ ${ }^{2}$ State Key Laboratory of Coal Resources and Safe Mining, China University of Mining and Technology, Beijing 100083, China \\ Correspondence should be addressed to Hongwei Wang; whw@cumtb.edu.cn
}

Received 12 May 2021; Accepted 22 July 2021; Published 6 August 2021

Academic Editor: Hualei Zhang

Copyright $\odot 2021$ Hongwei Wang et al. This is an open access article distributed under the Creative Commons Attribution License, which permits unrestricted use, distribution, and reproduction in any medium, provided the original work is properly cited.

\begin{abstract}
As an extra-thick hard roof is a significant contributing factor to frequently induced sudden roof collapse accidents and coal bursts, this study investigates the relationship between extra-thick hard roof movement and mining-induced stress using physical experiments and numerical simulation methods based on mining activities in a longwall panel in the Yima mining area, Henan province, China. The results suggested that the movement and failure processes of the extra-thick roof could be divided into three main periods: the undisturbed, movement stabilization, and sudden collapse periods. The roof displacement remained essentially unchanged during the undisturbed period. During the movement stabilization period, the displacement gradually increased into the upper roof. However, the extra-thick main roof remained undisturbed until the immediate roof experienced its fourth periodic caving in the physical model. Consequently, the displacement expanded rapidly into the extra-thick main roof during the sudden collapse period and the strain energy was violently released when it accumulated in the extra-thick main roof. Additionally, the mining-induced stress was characterized by a sudden decrease in the gradual increase trend when the extra-thick roof instantly collapsed. The deformation and fracture of the extra-thick roof could cause a sudden decrease in the mining-induced stress and lead to continuous and unstable subsidence pressure exerted on the mining panel and roadway. This significantly contributes to the occurrence of coal bursts.
\end{abstract}

\section{Introduction}

An extra-thick hard roof is the strata with large thickness and high strength occurring above a coal seam or a thin immediate roof. Large area movement and unstable fracture of the extra-thick hard roof are significant hazards threatening safe production in coal mines. It will cause extensive damage to the entire stope and is an important factor of inducing typical dynamic disasters such as coal bursts [1-3]. In general, a sudden and violent collapse of the extra-thick hard roof can release masses containing deformation energy and cause coal bursts during longwall panel advancement where machinery and workers assemble.
The frequent extra-thick roof collapse events caused by mining activities have made an important influence on the safety of coal mine production for several years. In November 2011, a severe coal burst resulted in heavy casualties and damaged the roadway section at the 21-221 mining face of the Qianqiu mine in the Yima mining area $[4,5]$. Although the accident occurrence was related to the $F_{16}$ thrust fault near the mining panel, the presence of a $550 \mathrm{~m}$ thick and hard conglomerate rock above the coal seam was also a key disaster factor. Therefore, dynamic movement evolution of the extra-thick roof is of primary interest in this study.

The deformation and instability of the extra-thick roof are a source of dynamic disasters. Scholars have performed 
analyses from different perspectives and obtained fruitful results on the extra-thick roof deformation [6-9]. Gao et al. [10] studied the mechanism of ground pressure induced by hard roof instability through physical experiment and field measurement. Zhao et al. [11] introduced the large-sized cantilever beam theory to calculate the caving step distance of the thick and hard roof. Ning et al. [12] investigated dynamic movement and fracturing of the thick and hard roof by microseismic monitoring technology. Shen et al. [13] found the strong influence of the fracture position of a thick hard roof on the roadway. Singh and Singh [14] assessed the effect of basic roof thickness on the strata caving behavior and stated that the caving span of basic roof fall increased linearly with the increase in basic roof thickness. Zhou et al. [15] stated that the solid backfill body is an effective way to control the deformation of hard roof and the hard roof's subsidence decreased as solid backfilling ratio increased. Wang et al. [16] found that overburden pressure induced a fracture in a thick hard roof after initial and periodic instability failure. In addition, extensive field investigation results have been obtained regarding the correlation between the movement of the thick hard roof and roadway failure $[17,18]$.

Due to the complexity, periodicity, and suddenness of the extra-thick roof collapses, the movement of the extra-thick roof is a significant determinant for underground coal mining activities. To acquire further knowledge of the dynamic movement and fracture of the extra-thick roof, integrated physical experiments and numerical simulations were conducted to study the relationship between displacement and mining-induced stress of the extra-thick roof. Moreover, the mechanism contributing to the sudden occurrence of coal bursts induced by the extra-thick roof collapse in the Yima mining area is introduced.

\section{Site Descriptions}

The Yima mining area contains several faults and synclines, as shown in Figure 1, and was selected as the principal geological background for this study. The Yima mining area is located south of Yima city, China, and covers five majorproducing coal mines, that is, the Gengcun, Yuejin, Yangcun, Changcun, and Qianqiu mines. The number of coal bursts occurring in the last 10 years is also presented in Figure 1.

The 21-221 panel operates with the longwall mining method to extract the no. 2 coal seam with a thickness of $5.59-37.48 \mathrm{~m}$. The generalized stratigraphy and important geotechnical parameters of the 21-221 mining panel in the Qianqiu mine are shown in Table 1. The 21-221 mining panel floor is siltstone with an average thickness of $26 \mathrm{~m}$. The 21-221 mining panel immediate roof is sandstone with an average thickness of $10 \mathrm{~m}$ and mudstone with an average thickness of $24 \mathrm{~m}$. The 21-221 mining panel basic roof is a 96.35-580.50 $\mathrm{m}$ thick conglomerate with a uniaxial compressive strength (UCS) of $45 \mathrm{MPa}$ measured by uniaxial compression test in the laboratory. Therefore, the basic roof is a typical extra-thick hard rock stratum, which is a characteristic stratigraphic feature of the Yima mining area. Because high overburden stress from extra-thick conglomerate rock acts on coal seams, coal bursts occur routinely in the Qianqiu mine.

\section{Physical Experiment of the Movement Characteristics of the Extra-Thick Hard Roof}

3.1. Physical Model Construction. In recent years, many investigators have conducted extensive physical geological engineering experiments to summarize the characteristics of ground subsidence, overburden rock displacement behavior, distribution characteristics of mining-induced stress, and even the fault activation process in mining engineering [1931]. To reproduce the process of extra-thick roof movement through physical experiments, the relationship between the physical model and field prototype must satisfy the similarity law [32-34]. In this study, three principal types of similarity law parameters were considered: the material strength, material geometry, and material density. The similarity parameters $C_{\sigma}, C_{L}$, and $C_{\rho}$ are the ratios of material strength, material geometry, and material density between the field prototype and physical model, respectively. In addition, all of these should satisfy the equation $C_{\sigma} / C_{\rho} \cdot C_{L}=1$. For the similar simulation experiment of mining engineering, when the qualitative analysis model is needed, the geometric similarity ratio of the model should be taken in the range of 50 to 200. As the main purpose of this paper is to explore the deformation and failure mechanism of an extra-thick hard roof, the physical model design should mainly meet the requirements of strength similarity theory. According to the geological conditions of the extra-thick hard roof and the objective conditions of the experiment system, the optimal geometric similarity ratio is determined as 100 . Meanwhile according to the maximum loading limit of the physical model and the mechanical parameters of rock strata, the strength similarity ratio is determined as 160 . Therefore, the similarity coefficients $C_{\sigma}, C_{L}$, and $C_{\rho}$ are considered as 160,100 , and 1.6, respectively. The similarity materials used to simulate rock strata in field prototypes contain fine sand, gypsum, lime, and water, which are widely used as binder and aggregate materials in physical experiments [19, 32-36].

Figure 2 shows that the physical model built on the experimental platform (GDSTM) has dimensions of $150 \times$ $90 \times 10 \mathrm{~cm}$. Therefore, the similarity thickness of siltstone, that of coal seam, that of sandstone mudstone, and that of conglomerate rock in this physical model are $5,5,10,24$, and $46 \mathrm{~cm}$, respectively. Because the full height mining scheme is adopted in the similar simulation experiment, this paper mainly studies the characteristics of extra-thick hard roof deformation and collapse under the influence of mining. In order to lay a higher hard roof as far as possible in the physical model, the thickness of coal seam is reduced to only $5 \mathrm{~cm}$. Five layers of rock strata with different similarity materials in physical experiment are made with five mixed proportions, as shown in Table 2 . The humidity change will cause the strength change of a similar material in physical experiment, resulting in the similarity error of mechanical conditions between the model and the prototype. The drying time of similar materials mainly depends on observation and 


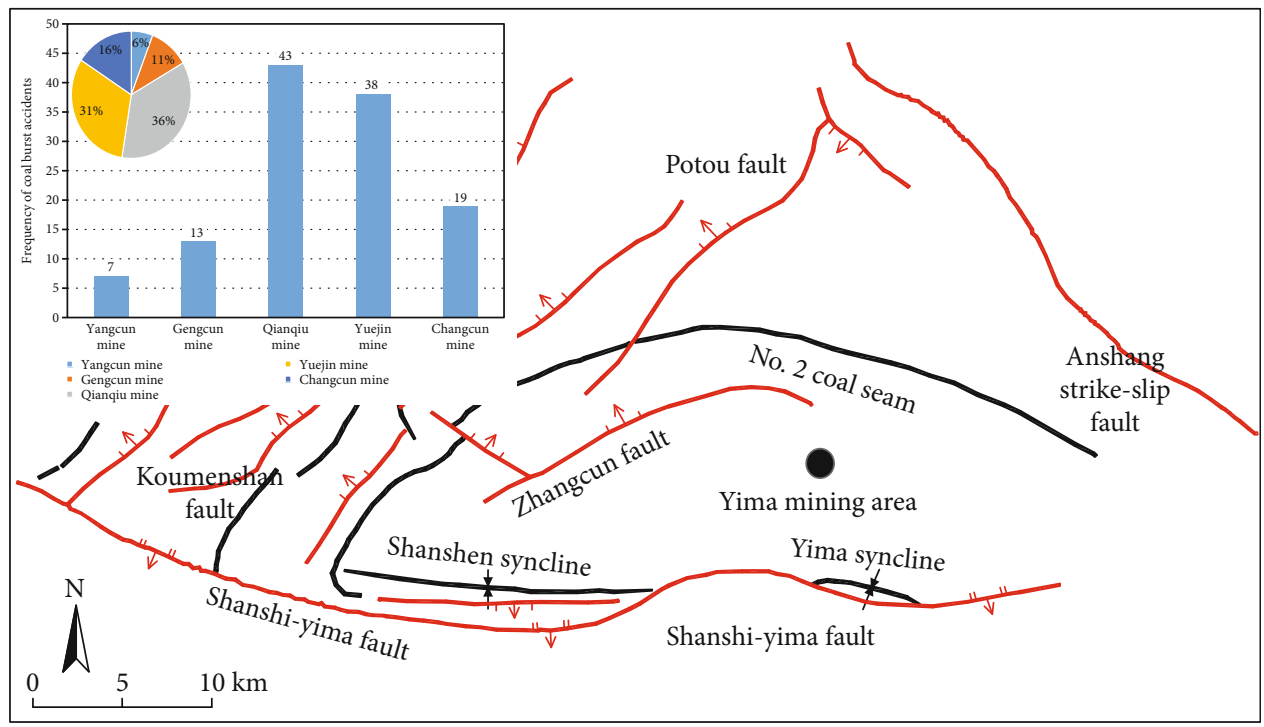

$$
\begin{aligned}
& >\text { Coal seam } \\
& \text { Fault } \\
& * \text { Syncline }
\end{aligned}
$$

\begin{tabular}{|c|c|c|c|c|c|}
\hline \multirow{2}{*}{ Rock strata } & \multicolumn{3}{|c|}{ Thickness (m) } & \multirow{2}{*}{$\begin{array}{l}\text { Density } \\
\left(\mathrm{kg} \cdot \mathrm{m}^{-3}\right)\end{array}$} & \multirow{2}{*}{$\begin{array}{l}\text { UCS } \\
\text { (MPa) }\end{array}$} \\
\hline & Max. & Min. & Mean & & \\
\hline $\begin{array}{l}\text { Conglomerate } \\
\text { rock }\end{array}$ & 580.50 & 96.35 & 550.00 & 2700 & 45 \\
\hline Mudstone & 42.20 & 4.40 & 24.00 & 2170 & 30 \\
\hline Sandstone & 27.00 & 0.00 & 10.00 & 2200 & 27 \\
\hline No. 2 coal seam & 37.48 & 5.59 & 9.60 & 1440 & 16 \\
\hline Siltstone & 32.81 & 0.30 & 26.00 & 2600 & 30 \\
\hline
\end{tabular}

FIGURE 1: Schematic map of geological structures in the Yima mining area.

TABLE 1: The generalized stratigraphy and geotechnical parameters.

empirical speculation to determine whether similar materials reach the expected strength. Generally, the drying time of similar materials is 3 to 7 days. The exact drying time depends on the weather conditions during the experiment. The drying time of similar materials is 5 days in this experiment.

The physical model stress boundary conditions in the experiment are loading according to the material strength ratio. The left, right, and top sides of the physical model are loading to $0.13 \mathrm{MPa}, 0.13 \mathrm{MPa}$, and $0.11 \mathrm{MPa}$, respectively.

3.2. Monitoring Plan and Analysis. Eleven stress sensors were positioned on the extra-thick conglomerate rock, $34 \mathrm{~cm}$ away from the coal seam, to monitor the mining-induced stress evolution during the longwall mining process. The horizontal space between the sensors was $10 \mathrm{~cm}$. The digital speckle image correlation technique was utilized to study the displacement evolution of overburden rock during continuous coal seam mining [37-39]. The technique can determine material displacement by following a specific speckle to calculate the movement path between two different pictures
[40-43]. The black speckles with a diameter of $1 \mathrm{~cm}$ in this study were arranged in an orderly manner on the rock strata surface to monitor the movement characteristics of the extrathick roof, as shown in Figure 2.

3.3. Test Results. In order to avoid extra-thick hard roof sudden collapse in the preliminary mining process, a coal pillar with a length of $20 \mathrm{~m}$ is reserved on the boundary of the on-site 21211 mining face. So, a coal pillar with a length of $20 \mathrm{~cm}$ was reserved on the right boundary of the model to reduce the boundary effect. The advancing length of the onsite 21221 mining face is $3 \mathrm{~m}$ to $8 \mathrm{~m}$ each step according to the field data. The average advancing length is $5 \mathrm{~m}$ each step under normal mining conditions. The coal seam was mined $5 \mathrm{~cm}$ each step from the right boundary to the left boundary of the physical model.

Figure 3 presented the mining process and roof caving during mining in the test. During the entire mining process in this test, the roof experienced five periodic caving, which showed distinct continuous failure with caving heights of 2 , $6,6,14$, and $36 \mathrm{~cm}$ above the goaf. The roof movement process could be divided into three main periods: the undisturbed, movement stabilization, and sudden collapse periods. When the mining face was mined at $35 \mathrm{~cm}$, the roof did not change significantly within a stable state. This stage was the undisturbed period, as shown in Figures 3(a) and 3 (b). With the development and connection of cracks in the roof strata, the roof separation phenomenon became increasingly conspicuous. However, the extra-thick roof was essential in the movement stabilization period, as shown in Figures 3(c)-3(g). Meanwhile, the roof progressively sank repeatedly and the roof caving height increased steadily from 2 to $14 \mathrm{~cm}$ during this period. The reason for the roof 


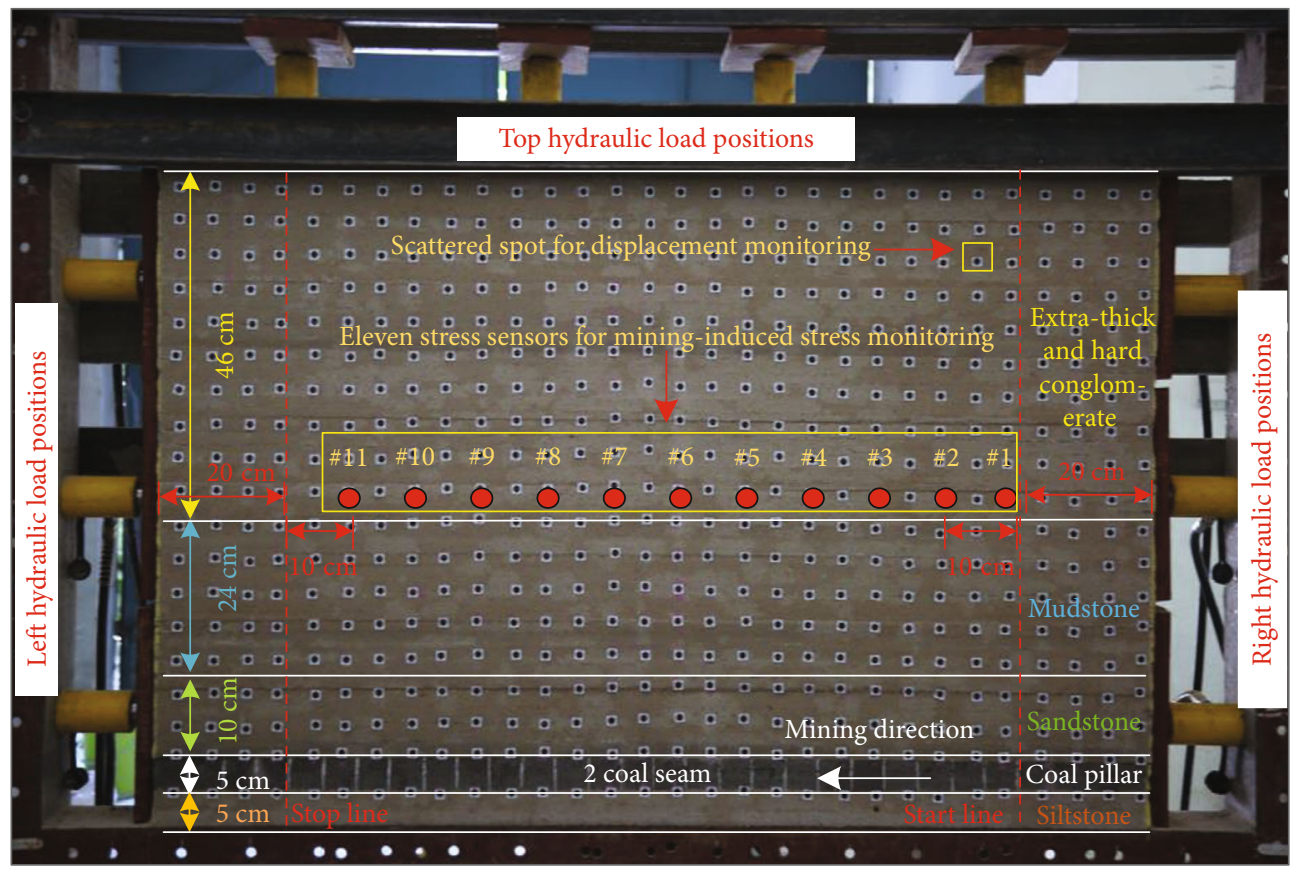

Figure 2: Physical model constructed on the GDSTM and general experimental monitoring plan.

TABLe 2: Parameters of the similar material.

\begin{tabular}{lccc}
\hline Rock strata & Fine sand : gypsum : lime: water & UCS of similar material (MPa) & UCS of prototype rock (MPa) \\
\hline Conglomerate rock & $6.0: 0.5: 0.5: 0.6$ & 0.28 & 44.8 \\
Mudstone & $7.0: 0.4: 0.6: 0.7$ & 0.19 & 30.4 \\
Sandstone & $7.0: 0.5: 0.5: 0.7$ & 0.17 & 27.2 \\
Coal seam & $8.0: 0.6: 0.4: 0.8$ & 0.10 & 16.0 \\
Siltstone & $7.0: 0.4: 0.6: 0.7$ & 0.19 & 30.4 \\
\hline
\end{tabular}

suspension for a long time is that the extra-thick hard roof has great strength and stiffness, which can bear large deformation. Deformation energy is gradually accumulated in the extra-thick hard roof during coal seam mining. The bending and subsidence of hard rock lead to forming the large separation area of the extra-thick hard roof. When the mining face was mined at $110 \mathrm{~cm}$, the roof collapse suddenly expanded into the extra-thick conglomerate in a large area, as shown in Figure 3(h). The roof movement showed an unstable dynamic change in behavior in the sudden collapse period. In this physical experiment, the extra-thick main roof collapse was only observed once when periodic roof caving occurred in the immediate roof. The structural instability of the extra-thick roof was a significant feature of large deformation.

In order to further analyze the spatial structure characteristics of the extra-thick roof in five times the caving state, Figure 4 showed spatial structure distribution of roof caving during advancement of the mining face. The roof caving areas at different stages were distinguished by different color boxes during the experiment process. As the mining face continued advancing and goaf area gradually increased, the caving space was gradually expanded. The development of roof caving was a dynamic process. The characteristic param- eters of fractured strata in caving areas were usually the caving height, high-level fractured rock span, low-level fractured rock span, and caving angle, further analyzed in Figure 5.

Low-level and high-level fracture rocks refer to the lowest and the uppermost fracture rock in the roof collapse area, respectively. They can generally describe the spatial range of the roof collapse area. The span of high-level fracture strata is obviously larger than that of low-level fracture strata in the roof collapse area. That is because the roof collapse area expands upward in the mining process of the coal seam. At the first caving, the fracture spans of the low-level and high-level strata were 35 and $32 \mathrm{~cm}$, respectively. The average fracture span of the low-level strata was $20 \mathrm{~cm}$ within the next four periodic roof caving. The fracture span of the high-level strata increased steadily except for the third periodic caving, as shown in Figure 5(a). Figure 5(b) shows the minimum and maximum collapse angles of $50^{\circ}$ and $56^{\circ}$, respectively. The caving angle showed little fluctuation during the five periodic caving. When the rock strata occur shear failure model, the caving angle between the failure surface and horizontal direction is approximately same under the same lithology condition. The caving angle is closely related to the internal friction angle of the rock stratum. With the advancement of mining faces, the extra-thick roof always 


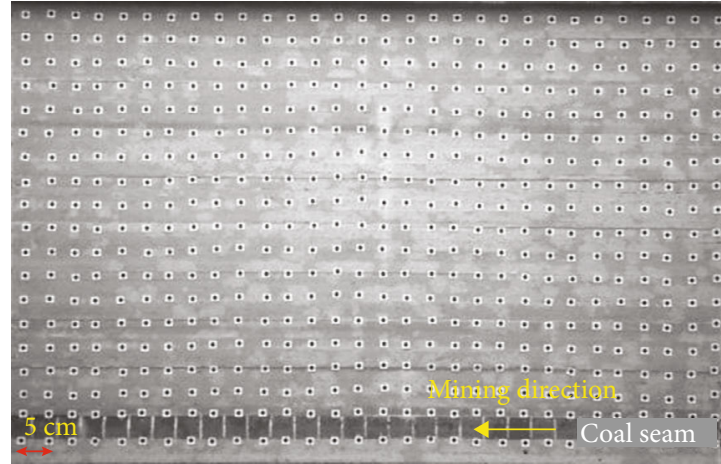

(a) Initial equilibrium state

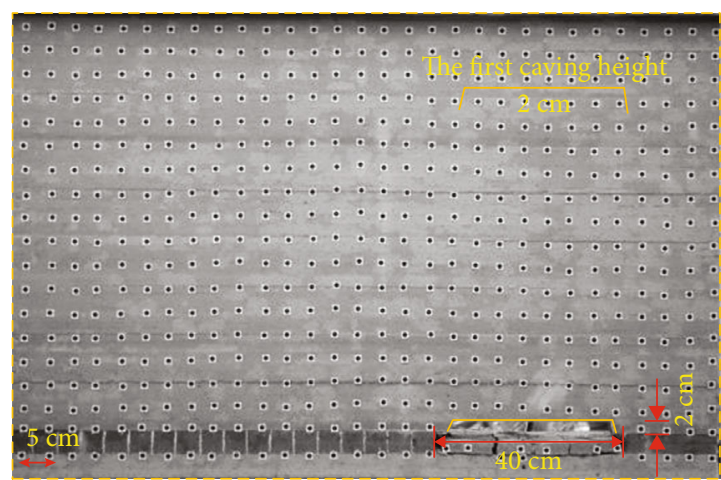

(c) Mining distance: $40 \mathrm{~cm}$

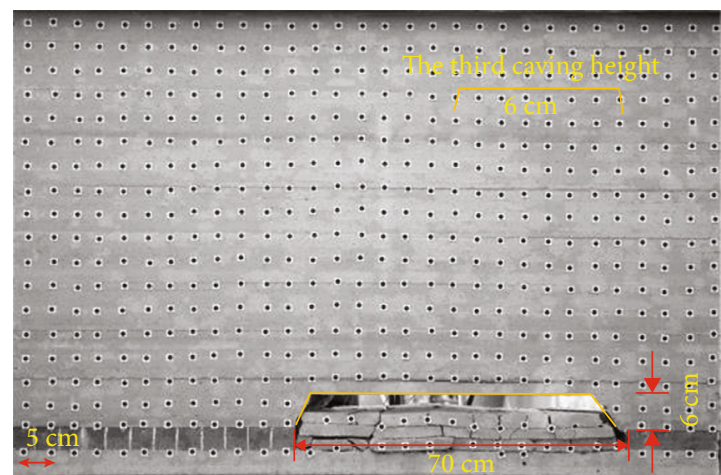

(e) Mining distance: $70 \mathrm{~cm}$

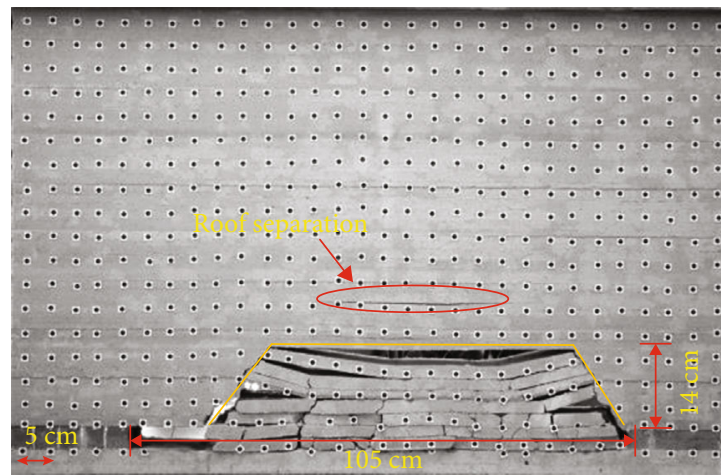

(g) Mining distance: $105 \mathrm{~cm}$

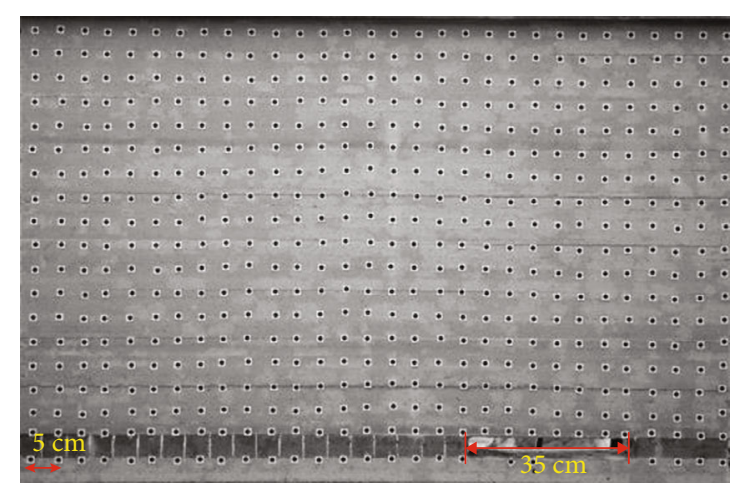

(b) Mining distance: $35 \mathrm{~cm}$

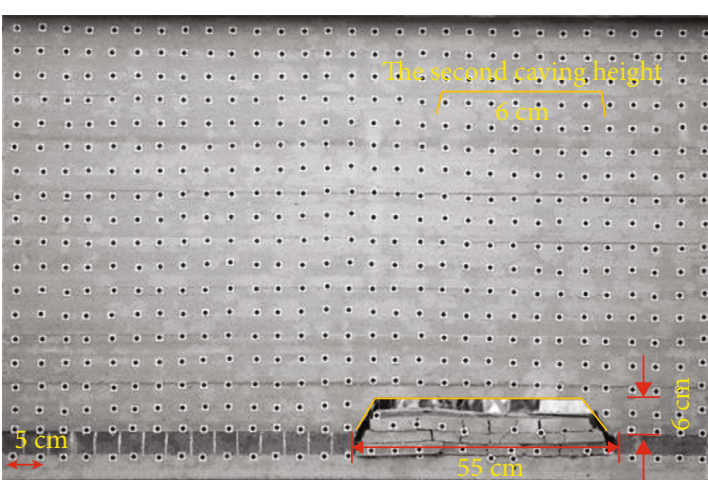

(d) Mining distance: $55 \mathrm{~cm}$

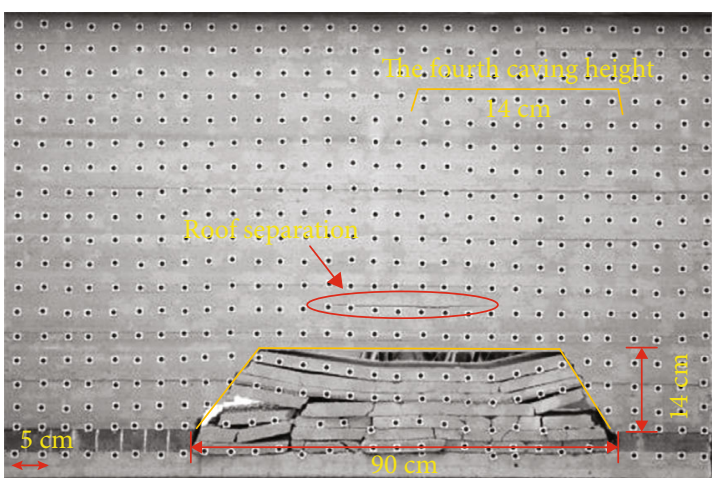

(f) Mining distance: $90 \mathrm{~cm}$

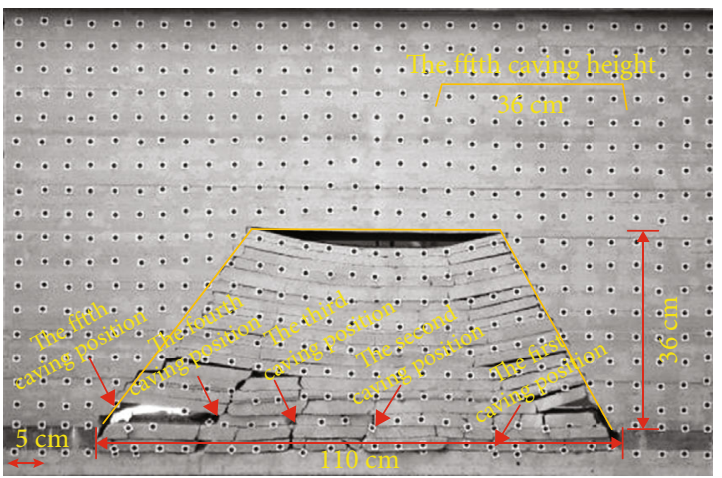

(h) Mining distance: $110 \mathrm{~cm}$

FIGURE 3: The movement state of the roof during coal seam mining in the physical model. 


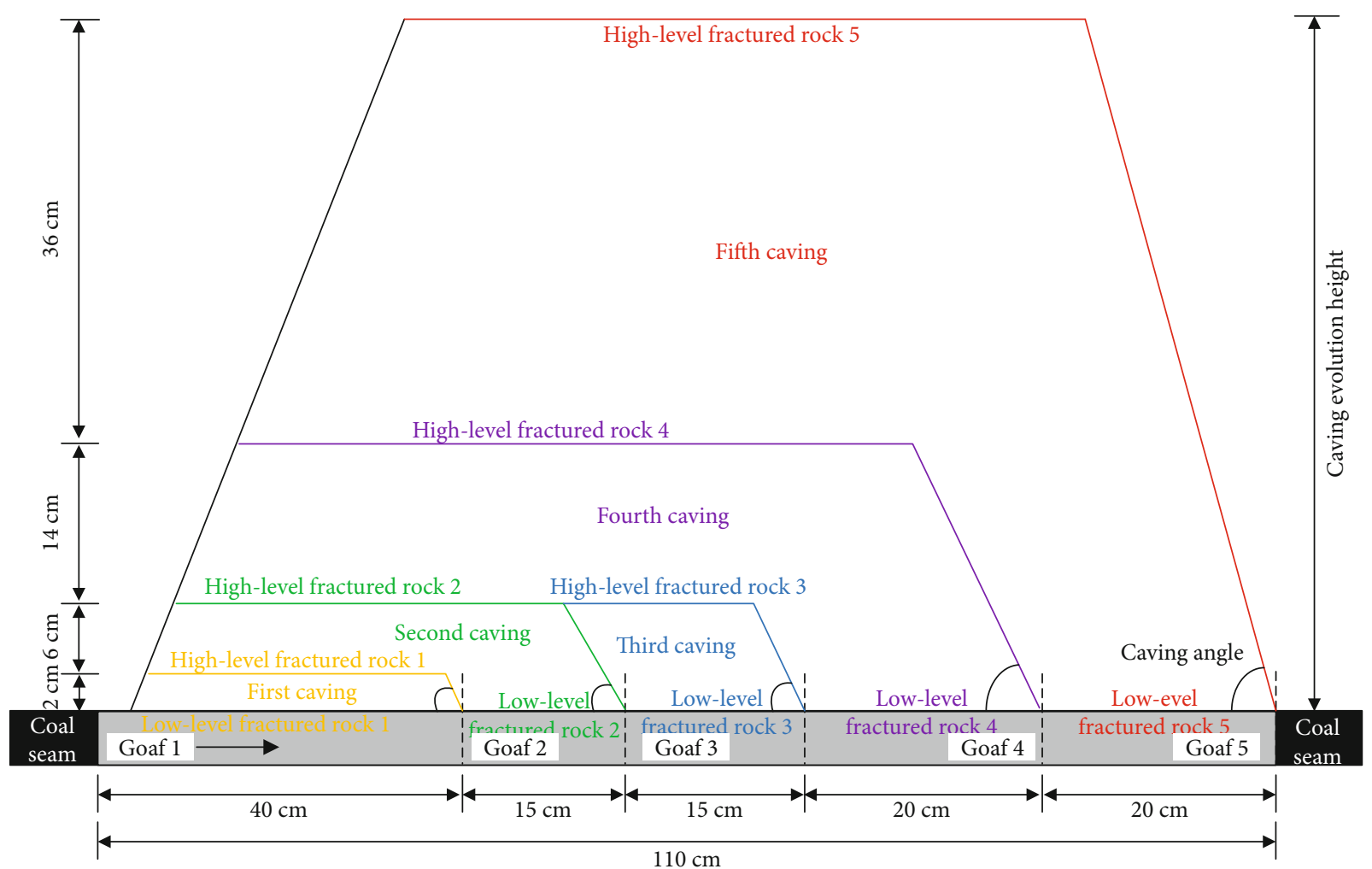

FIgURE 4: Spatial distribution of roof caving during advancement of the mining face.

experienced change of state alternating between stability and instability after the first roof weighting, and roof pressure release occurred periodically. Because the lithology of low-level strata was mudstone, the breaking span of lowlevel strata remained stable. However, the lithology of high-level strata was composed of mudstone and extrathick conglomerates, and the breaking span of high-level strata changed frequently.

The influence of mining disturbance on the extra-thick roof was relatively small in the undisturbed period, and the entire model vertical displacement was zero, as shown in Figure 6(a). During the movement stabilization period, the disturbance effect of continuous mining gradually became obvious. The extra-thick roof experienced five caving in succession and collapsed rock fills in the goaf. The caving strata displacement in the center of the goaf increased to $5.5 \mathrm{~cm}$ due to repeated compression. Because of the rock volume expansion, the strata displacement far away from the center of the mining face gradually decreased. In addition, the displacement gradually increased into the upper roof and could be observed only in the immediate roof and the extra-thick roof was not disturbed by the mining activities, as shown in Figures 6(b)-6(e). However, the mining face was mined to a distance of $110 \mathrm{~cm}$ in the sudden collapse period and Figure 6(f) shows that the displacement expanded rapidly into the extra-thick roof and the energy accumulated in the hard conglomerate was suddenly released.

With the mining face advancement, the stress balance of the extra-thick roof was broken due to roof collapse. The stress was redistributed to form a new overburden equilibrium structure. Five stress monitoring points marked as \#1,
$\# 4, \# 6$, \#8, and \#11 in the extra-thick conglomerate were selected to analyze the characteristics of stress variation, as shown in Figure 7 . When the mining face was advanced to a distance from $0 \mathrm{~cm}$ to $70 \mathrm{~cm}$, the stress of all monitoring points gradually increased. And the stress of each monitoring point had slightly fluctuated at the same mining distance. When the mining face was advanced to a distance from $75 \mathrm{~cm}$ to $110 \mathrm{~cm}$, the stress of $8 \#$ monitoring point in extrathick roof would go through two stages, including sharp increase stage and sharp decrease stage. Therefore, the stress variation and the movement state of the extra-thick roof are combined for integrated analysis. During the undisturbed period, the mining disturbance influence on the extra-thick conglomerate increased. The extra-thick roof stress gradually increased, and the deformation energy slowly accumulated in the extra-thick conglomerate. In the movement stabilization period, the extra-thick conglomerate stress increased to the peak stress. In the sudden collapse period, the extra-thick conglomerate stress dropped suddenly. Because of the extensive deformation energy of the extra-thick conglomerate, the deformation energy was violently released in a sudden manner when the extra-thick conglomerate collapsed over a large area. Therefore, the mining-induced stress was characterized by a sudden decrease in the gradually increasing trend when the extra-thick roof suddenly collapsed.

\section{Movement Evolution Characteristics of the Extra-Thick Hard Roof}

4.1. Numerical Model. A three-dimensional distinct element code (3DEC) has certain advantages for simulating large 


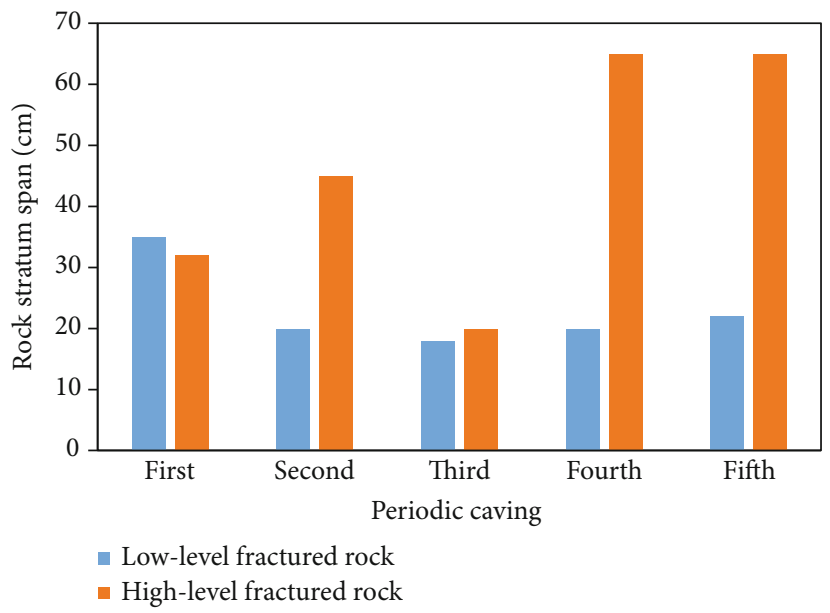

(a) Fractured rock strata span

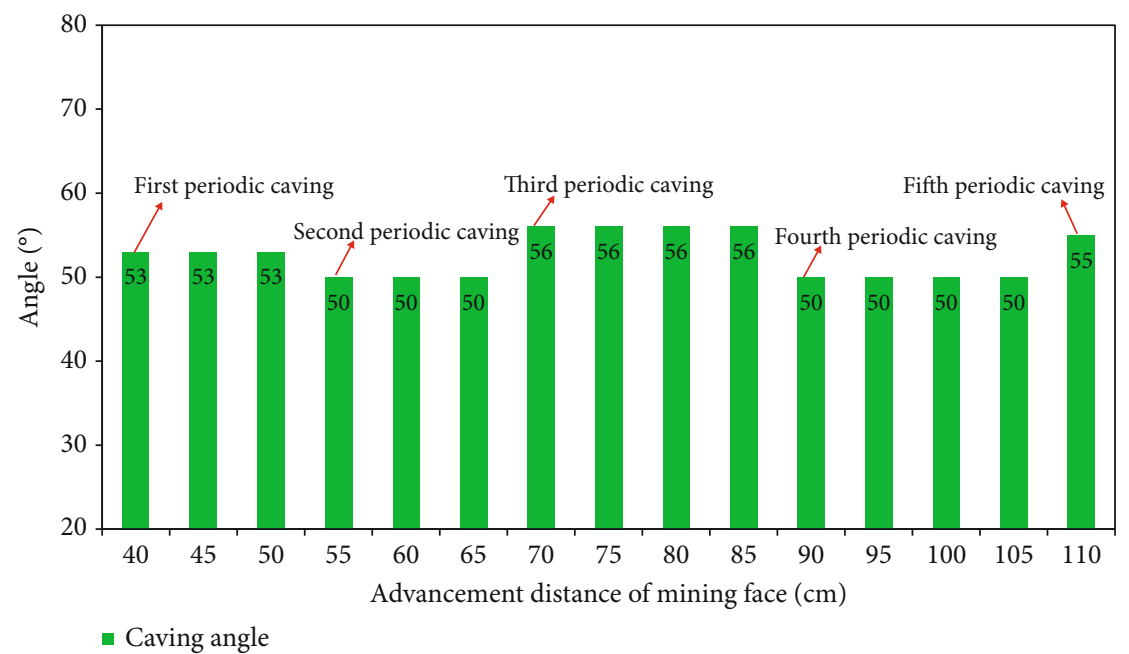

(b) Fractured rock caving angle

FIGURE 5: Fractured rock parameters of five periodic caving of extra-thick roof.

movement and large deformation of a massive system under static or dynamic loading of discontinuous medium (such as jointed rock mass). It is suitable for applying to simulate the movement characteristics of an extra-thick roof under the influence of mining disturbance. The material in the 3DEC model was divided into two parts: the rock block as the continuity and the structural plane between rock blocks as the discontinuity. Considering the same physical model dimensions, a geometrical dimension of $150 \times 10 \times 90 \mathrm{~m}$ was established in the 3DEC model, as shown in Figure 8.

Combined with the specific characteristics of each rock stratum, the relevant mechanical parameters of the strata and structure plane between blocks in the numerical mode were shown in Tables 3 and 4, respectively.

They were partially checked after several debugging cycles based on the geological parameters of the 21-221 longwall face. A vertical stress of $20.0 \mathrm{MPa}$ was applied at the top of the numerical model. Because the maximum dominant stress in the 21-221 longwall face is horizontal stress, a horizontal stress of $23.4 \mathrm{MPa}$ was applied to the two-boundary numerical model.
The mining face was mined at a distance of $5 \mathrm{~m}$ along the coal seam from the left side to the right side of the numerical model. The entire model advanced 22 times in total, making the total mining distance of $110 \mathrm{~m}$.

4.2. Extra-Thick Roof Collapse Displacement. The displacement and velocity vectors of the extra-thick roof were analyzed to describe the roof movement behavior.

As the mining face advanced to $20 \mathrm{~m}$, there was no obvious extra-thick roof movement but the immediate roof had a triangular shape displacement, as shown in Figure 9(a). As the mining face advanced to $40 \mathrm{~m}$, the immediate roof collapsed under the action of gravity. The main roof, $24 \mathrm{~m}$ above the coal seam, exhibited a distinct separation phenomenon, shown in Figure 9(b). The caving area and maximum displacement of the immediate roof gradually increased as the mining face continued advancing. Due to the support of the collapsed rock mass and coal seam to the intact rock stratum, the extra-thick roof was separated from the immediate roof, as shown in Figures 9(c) and 9(d). Bending and subsidence occurred in the extra-thick conglomerate and the roof 


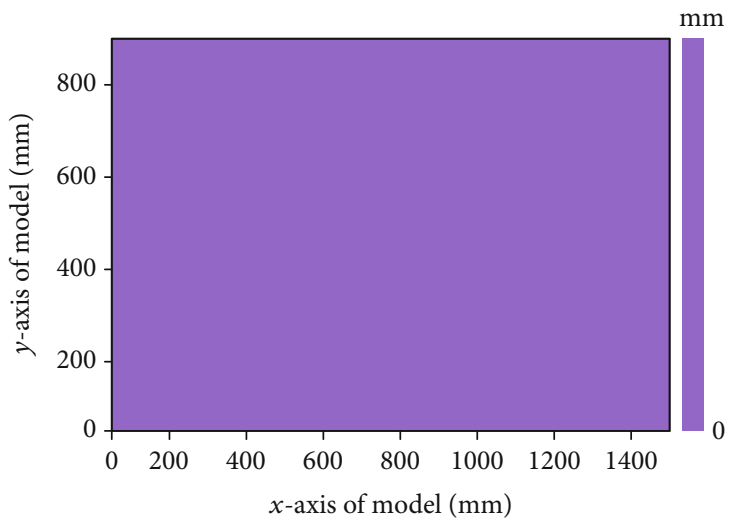

(a) Initial equilibrium state

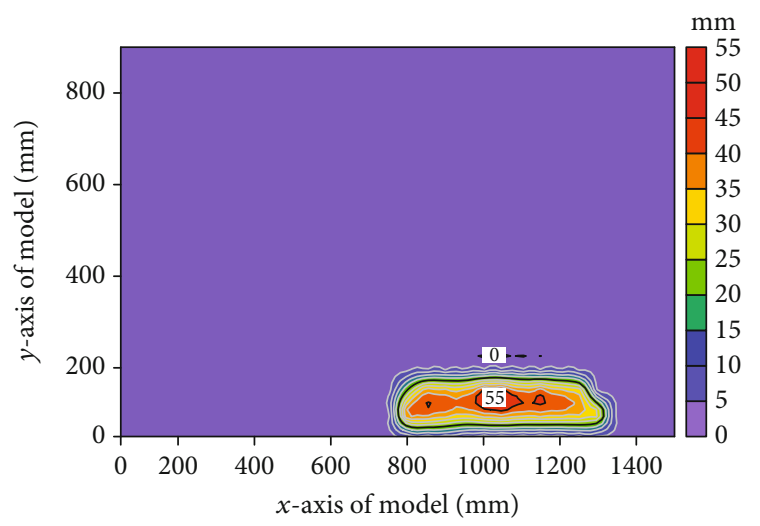

(c) The second periodic caving

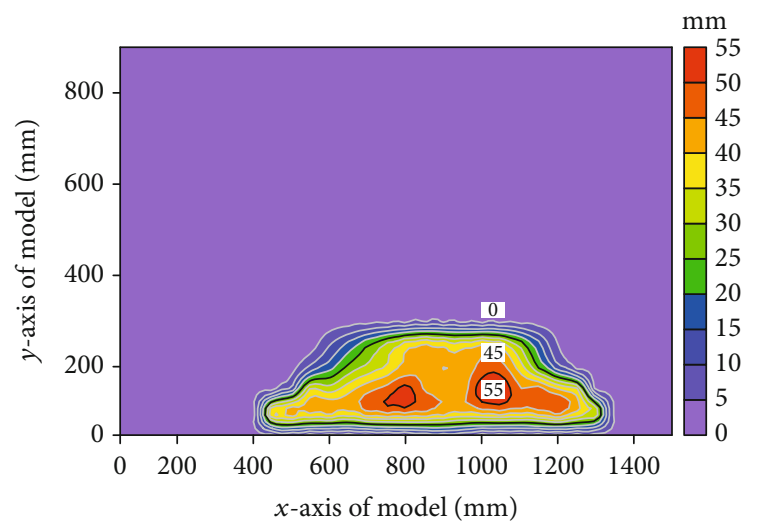

(e) The fourth periodic caving

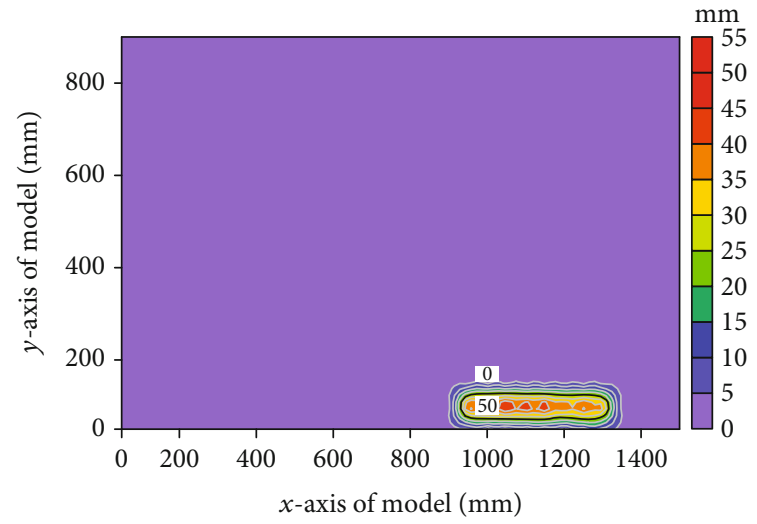

(b) The first periodic caving

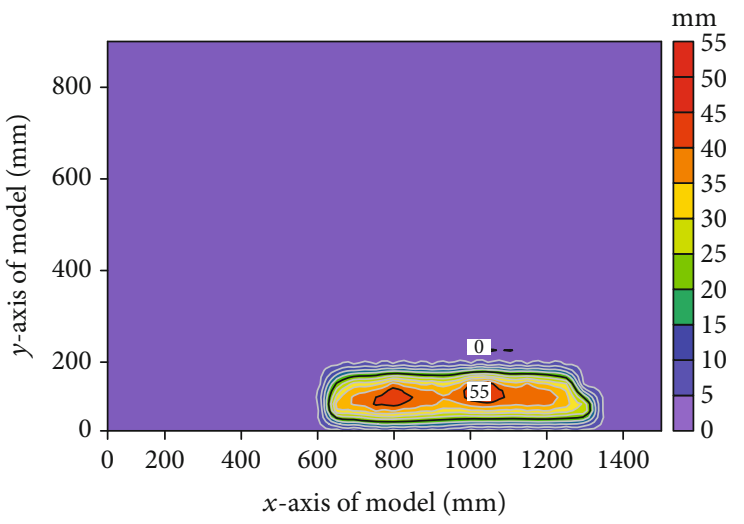

(d) The third periodic caving

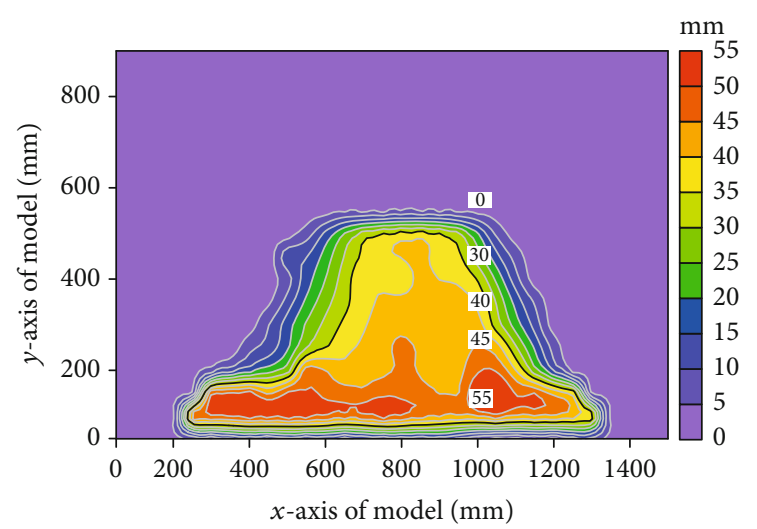

(f) The fifth periodic caving

Figure 6: Vertical displacement variation of five periodic caving of extra-thick roof.

separation area expanded further, as shown in Figure 9(e). The extra-thick roof moved downward, and the roof displacement increased gradually as the mining face advanced to $110 \mathrm{~m}$, as shown in Figure 9(f). The extra-thick roof collapsed in a large area, which could easily cause coal bursts. Clearly, the broken strata of the extra-thick roof successively progressed through separation, bending subsidence, closing separation, and caving compaction processes.

The rock strata above the mining face began to move down slowly, and the velocity vector appeared at the immediate roof, as shown in Figure 10(a). The extra-thick roof caving in small areas led to stress redistribution, and the velocity vector of the roof enlarged as the mining face advanced to $40 \mathrm{~m}$, as shown in Figure 10(b). As the mining face further was advancing, the collapsed rock strata far away from the mining face entered the compaction state and the velocity vector was essentially zero, as shown in Figures $10(\mathrm{c})$ and $10(\mathrm{~d})$. In addition, there was a wide range of unstable roofs near the mining face moving to the goaf, and the roof separation gap enlarged. The extra-thick conglomerate had a downward movement trend with a small velocity, as shown in Figure 10(e). It moved further to the goaf, and the velocity vector of the extra-thick conglomerate increased gradually as the mining face advanced to $110 \mathrm{~m}$, as 


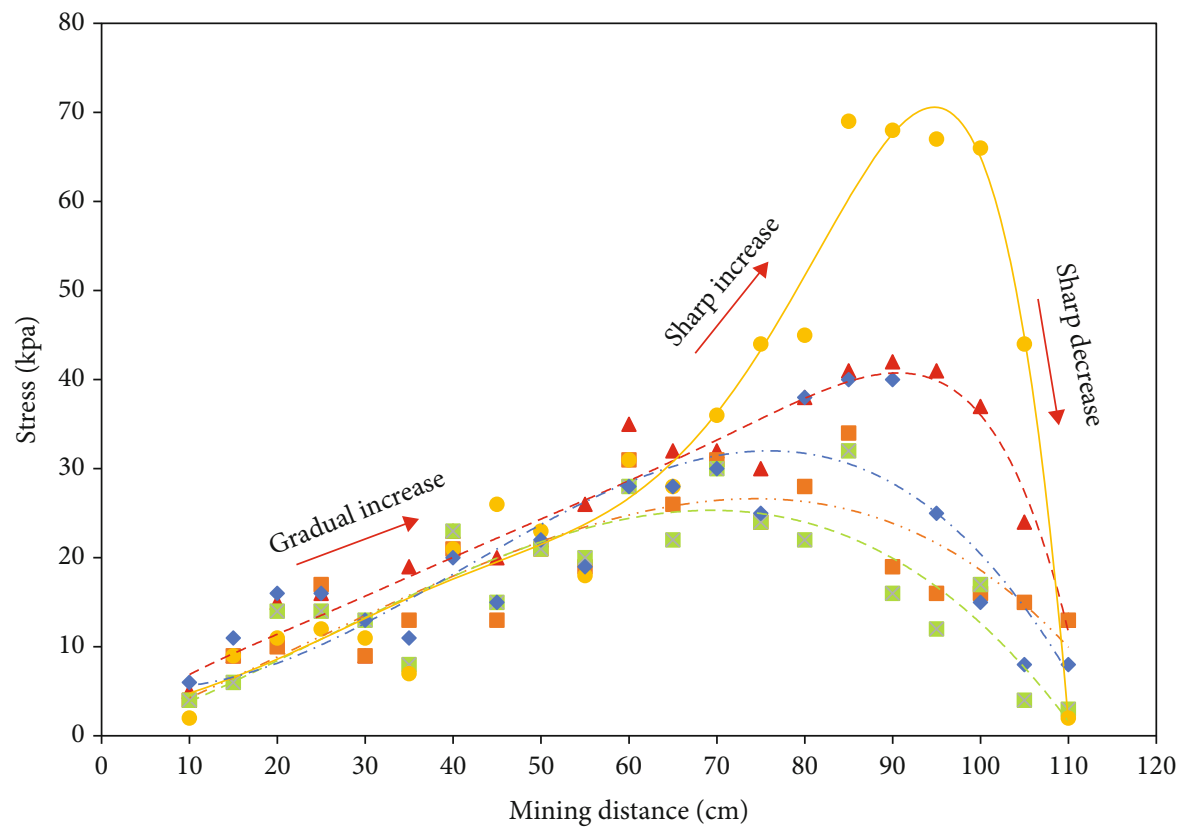
$\Delta$ \#1
- - - \#1 fitting curve
- \#4
-... \#4 fitting curve
뭉
- $\# 8$
-. - \#6 fitting curve
- \#11
_- \#8 fitting curve
-. \#11 fitting curve

Figure 7: Stress variation detected from stress sensors marked as \#1, \#4, \#6, \#8, and \#11 during advancement of the mining face.

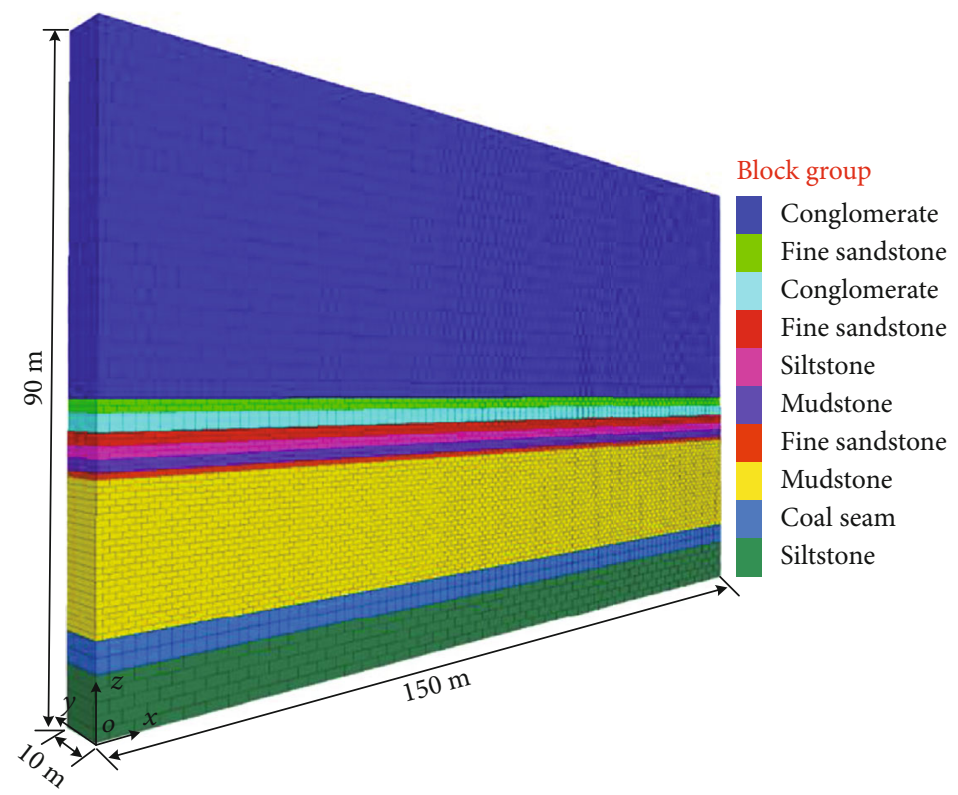

(a) Rock block model

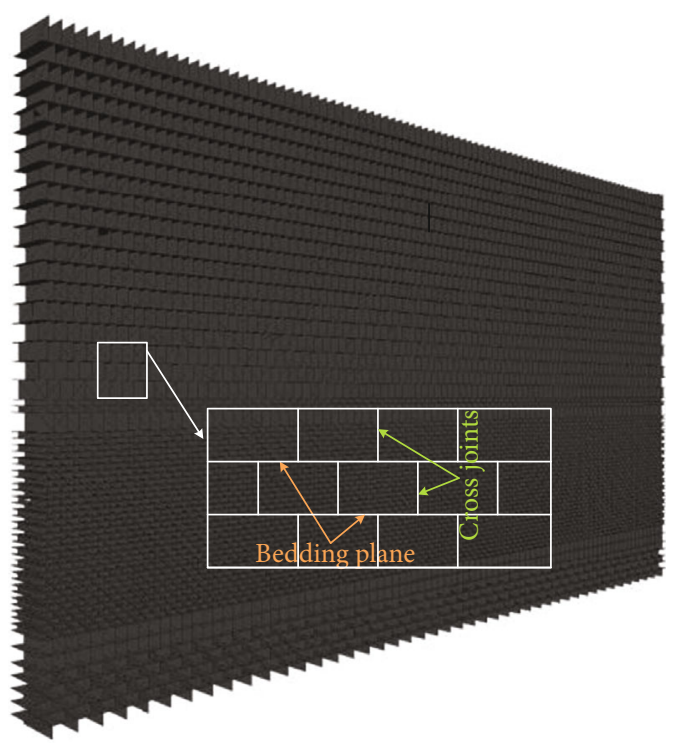

(b) Structure plane between blocks

FIGURE 8: Schematic diagram of the extra-thick roof in the 3DEC model. 
TABle 3: Physical and mechanical parameters of rock strata.

\begin{tabular}{|c|c|c|c|c|c|c|c|}
\hline Rock strata & $\begin{array}{l}\text { Thickness } \\
(\mathrm{m})\end{array}$ & $\begin{array}{l}\text { Density } \\
\left({\left.\mathrm{kg} . \mathrm{m}^{-3}\right)}^{-3}\right.\end{array}$ & $\begin{array}{l}\text { Bulk modulus } \\
\quad(\mathrm{GPa})\end{array}$ & $\begin{array}{l}\text { Shear modulus } \\
(\mathrm{GPa})\end{array}$ & $\begin{array}{c}\text { Cohesion } \\
(\mathrm{MPa})\end{array}$ & $\begin{array}{c}\text { Friction angle } \\
\left({ }^{\circ}\right)\end{array}$ & $\begin{array}{c}\text { Tensile strength } \\
(\mathrm{MPa})\end{array}$ \\
\hline Conglomerate & 39 & 2865 & 20.33 & 17.50 & 11.85 & 40 & 10.32 \\
\hline $\begin{array}{l}\text { Fine } \\
\text { sandstone }\end{array}$ & 2.0 & 2873 & 9.18 & 8.75 & 7.51 & 30 & 6.65 \\
\hline Conglomerate & 3.0 & 2865 & 20.33 & 17.50 & 11.85 & 40 & 10.32 \\
\hline $\begin{array}{l}\text { Fine } \\
\text { sandstone }\end{array}$ & 2.0 & 2873 & 9.18 & 8.75 & 7.51 & 30 & 6.65 \\
\hline Siltstone & 2.0 & 2707 & 12.82 & 10.02 & 8.97 & 30 & 8.65 \\
\hline Mudstone & 2.0 & 2461 & 6.11 & 5.49 & 4.49 & 20 & 4.30 \\
\hline $\begin{array}{l}\text { Fine } \\
\text { sandstone }\end{array}$ & 1.0 & 2873 & 9.18 & 8.75 & 7.51 & 30 & 6.65 \\
\hline Mudstone & 24 & 2461 & 6.11 & 5.49 & 4.49 & 20 & 4.30 \\
\hline Coal seam & 5.0 & 1440 & 4.67 & 4.47 & 3.40 & 26 & 3.06 \\
\hline Siltstone & 10 & 2873 & 9.18 & 8.75 & 7.51 & 30 & 6.65 \\
\hline
\end{tabular}

TABLE 4: Mechanical parameters of structure plane between blocks.

\begin{tabular}{|c|c|c|c|c|c|}
\hline Rock strata & Normal stiffness (GPa) & Shear stiffness $(\mathrm{GPa})$ & Tensile strength $(\mathrm{MPa})$ & Friction angle $\left({ }^{\circ}\right)$ & Cohesion $(\mathrm{MPa})$ \\
\hline Conglomerate & 12.0 & 15.0 & 6.14 & 10 & 7.0 \\
\hline Fine sandstone & 5.0 & 5.0 & 4.10 & 8 & 4.5 \\
\hline Conglomerate & 12.0 & 15.0 & 6.14 & 10 & 6.4 \\
\hline Fine sandstone & 4.0 & 5.0 & 4.10 & 8 & 4.5 \\
\hline Siltstone & 4.0 & 4.0 & 3.61 & 8 & 4.4 \\
\hline Mudstone & 1.6 & 4.8 & 1.30 & 7 & 2.2 \\
\hline Fine sandstone & 5.0 & 5.0 & 4.10 & 8 & 5.5 \\
\hline Mudstone & 1.6 & 4.8 & 1.30 & 7 & 2.2 \\
\hline Coal seam & 1.4 & 1.2 & 1.02 & 6 & 1.3 \\
\hline Siltstone & 5.0 & 5.0 & 4.10 & 8 & 4.5 \\
\hline
\end{tabular}

shown in Figure 10(f). Because enormous deformation energy is released by the collapse of the extra-thick conglomerate, the extra-thick roof is in the most dangerous state for mining face safety.

\section{Mining-Induced Stress Evolution Characteristics of the Extra-Thick Hard Roof}

5.1. Numerical Model. A finite difference program FLAC ${ }^{3 \mathrm{D}}$ is applied to simulate the mining-induced stress distribution characteristics of an extra-thick hard roof during the advancement of the mining face. By building the appropriate constitutive relation of geological materials in FLAC ${ }^{3 \mathrm{D}}$, the progressive mining-induced stress evolution of elasticplastic rock mass is effectively tracked. Combined with the results of physical experiment, the stress evolution of the extra-thick roof in the numerical model was comparatively analyzed.

A numerical model in FLAC ${ }^{3 \mathrm{D}}$ with 12 stress monitoring points numbered \#1-\#12 located on extra-thick conglomerate rock was established. The location of the stress monitoring points corresponds to the stress sensor distribution in the physical model to monitor mining-induced stress in the extra-thick conglomerate, as shown in Figure 11. Adjacent stress monitoring points were placed $10 \mathrm{~m}$ apart. A vertical stress of $20.0 \mathrm{MPa}$ was applied at the top of the numerical model, and a horizontal stress of $23.4 \mathrm{MPa}$ was applied to the two side boundaries. Moreover, the horizontal boundary displacement was limited and the vertical displacement of the numerical model base was fixed. The physical and mechanical parameters of rock strata in the FLAC ${ }^{3 \mathrm{D}}$ model after several debugging cycles were used, as shown in Table 5 .

5.2. Stress Distribution Characteristics in the Extra-Thick Roof. As the mining face was advancing, the vertical stress in the extra-thick roof was gradually released. The release of vertical stress showed that the absolute value of stress decreased and the release area of vertical stress gradually increased into the upper roof, as shown in Figures 12(a)12(f). The supportive effect of the original coal seam on the extra-thick roof gradually disappeared. The effect of model top loading and gravity caused bending subsidence of the extra-thick roof. As the mining face advanced to $110 \mathrm{~m}$, the extra-thick roof experienced the largest stress release.

As shown in Figure 13, there were five stages of severe stress change in the extra-thick conglomerate during coal 


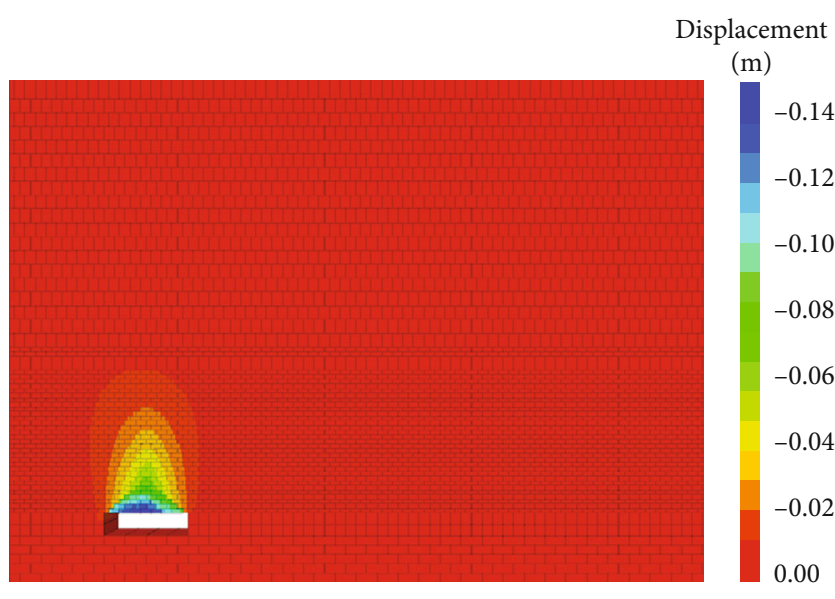

(a) Mining distance: $20 \mathrm{~cm}$

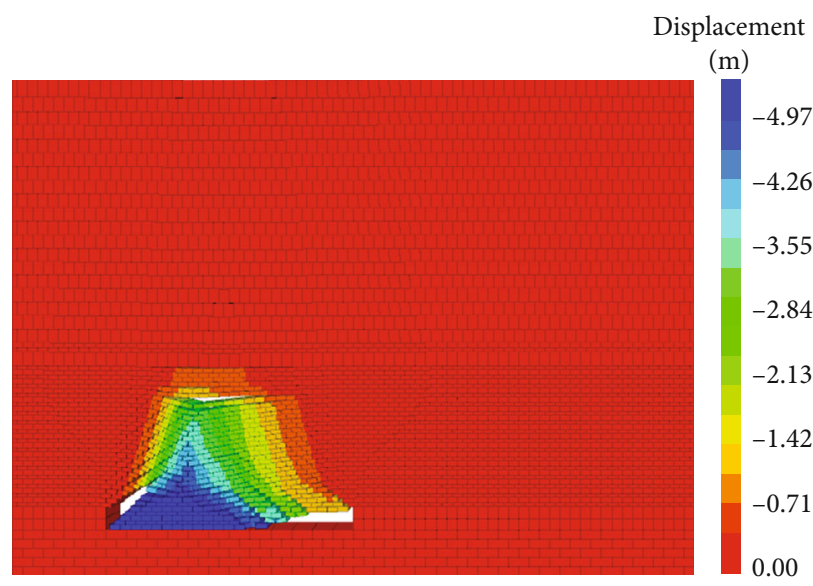

(c) Mining distance: $55 \mathrm{~cm}$

Displacement

(m)

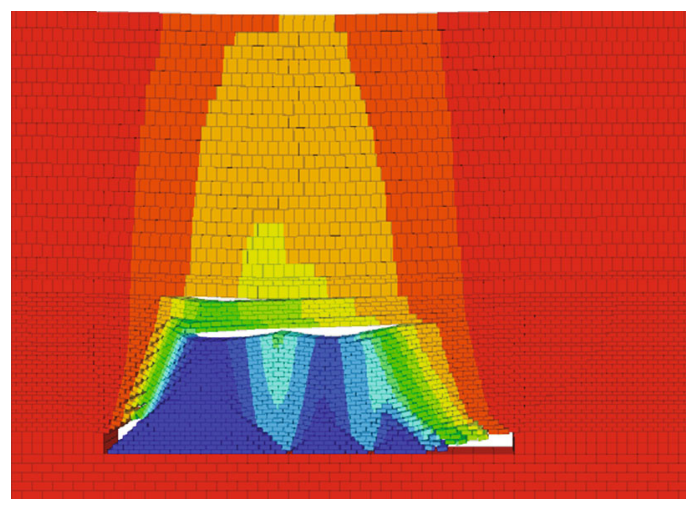

(e) Mining distance: $90 \mathrm{~cm}$
Displacement

(m)

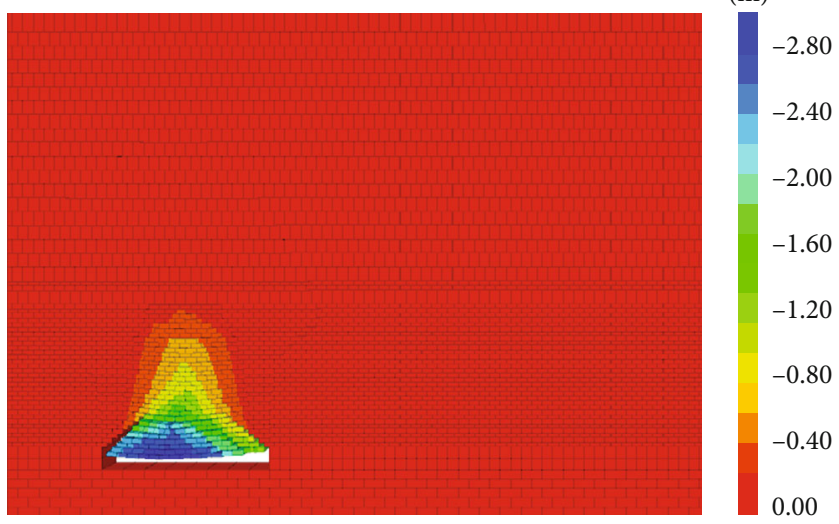

(b) Mining distance: $40 \mathrm{~cm}$

Displacement

(m)

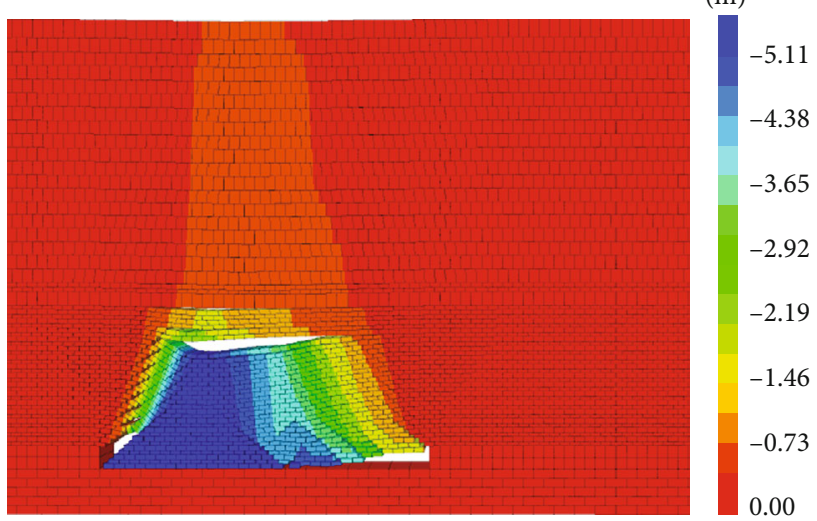

(d) Mining distance: $70 \mathrm{~cm}$

Displacement

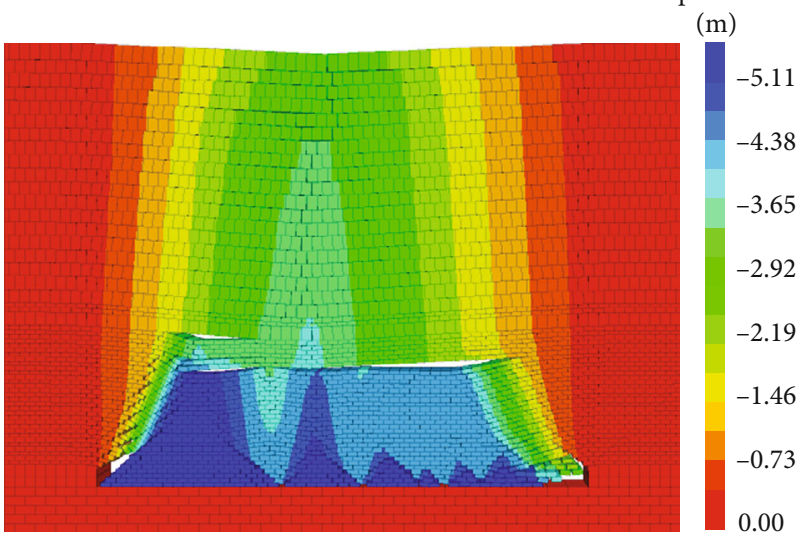

(f) Mining distance: $110 \mathrm{~cm}$

Figure 9: Vertical displacement variation of the roof during the advancement of the mining face.

seam mining. As the mining face advanced to 40, 55, 75, 90, and $110 \mathrm{~m}$ in the numerical model, the roof experienced five periodic caving at five mining stages. When the roof collapsed for the fourth time, the response of the extra-thick conglomerate was more intense and the stress of the extrathick conglomerate was released. When the extra-thick roof collapsed for the fifth time, the stress of the extra-thick conglomerate changed violently and dropped abruptly.

To confirm the reliability of the numerical simulation results, the mining-induced stress obtained from the physical experiment was compared with that obtained from numerical simulation. In this study, the stress change per 


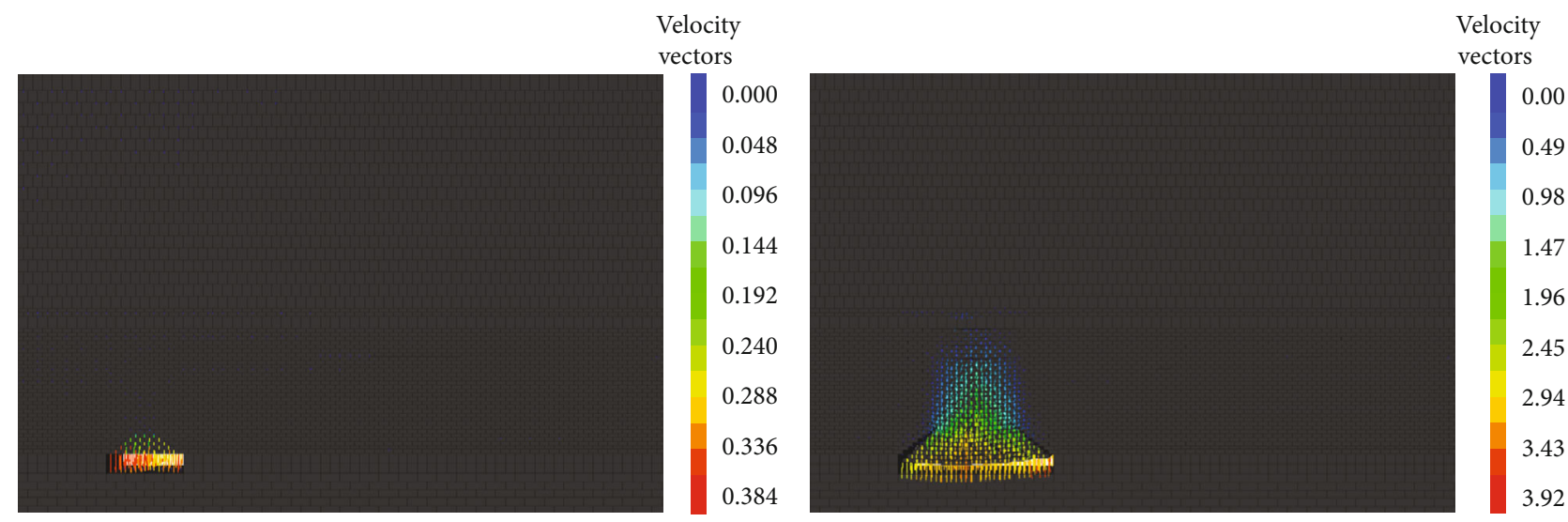

(a) Mining distance: $20 \mathrm{~cm}$

(b) Mining distance: $40 \mathrm{~cm}$

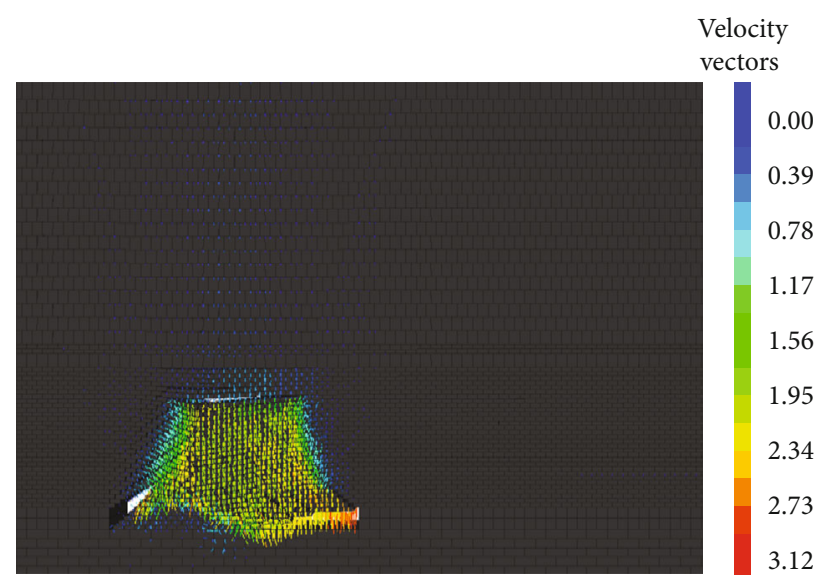

(c) Mining distance: $55 \mathrm{~cm}$

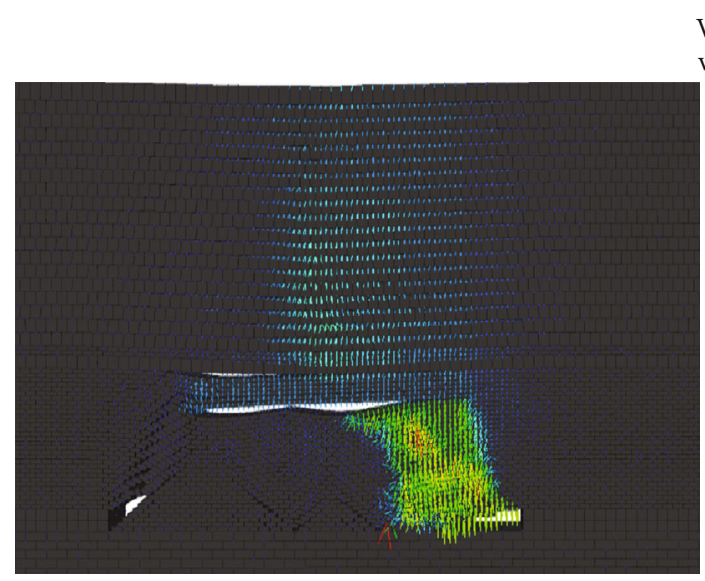

(e) Mining distance: $90 \mathrm{~cm}$

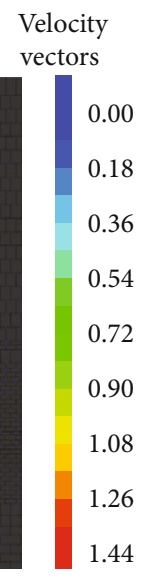
ctors

FIGURE 10: Velocity vector variation of the roof during the advancement of the mining face. meter of the $\# 8$ monitoring point at the same position as the numerical simulation and physical experiment in the mining face advancement was selected for comparative analysis.

Figure 14 showed that the stress change per meter obtained from physical experiments was consistent with that obtained from numerical simulation. In the early stage of coal mining, the stress fluctuation in the extra-thick roof was small. But when the mining face advanced to $110 \mathrm{~m}$, there was a violent fluctuation, indicating that the disturbance of coal mining to extra-thick conglomerate reached its maximum. The fifth caving of the extra-thick roof occurred in the goaf and the stress changed violently; the stress variation behavior at the \#8 measuring point at the same position between numerical simulation and physical experiment was basically synchronous. 


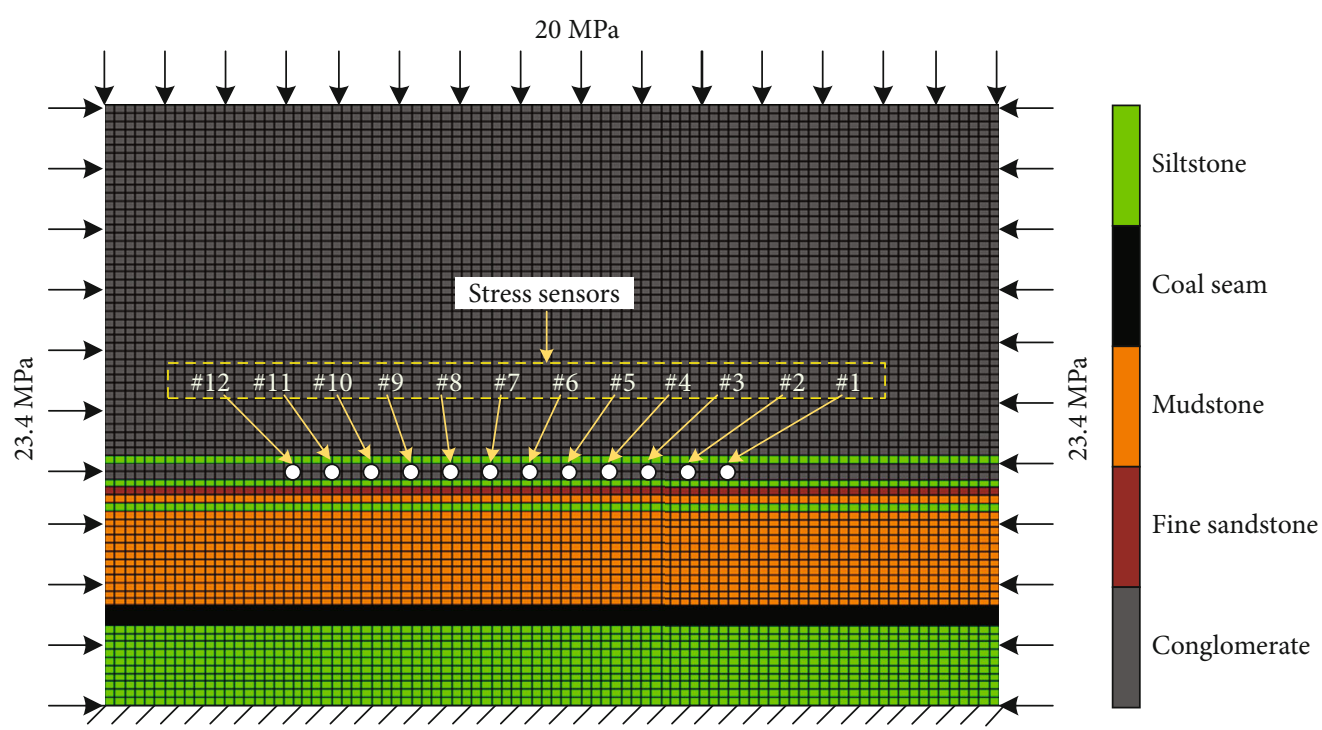

FIGURE 11: Numerical model of the extra-thick roof in FLAC ${ }^{3 \mathrm{D}}$.

TABLE 5: Physical and mechanical parameters of rock strata in the FLAC ${ }^{3 \mathrm{D}}$ model.

\begin{tabular}{|c|c|c|c|c|c|c|c|}
\hline Rock strata & $\begin{array}{c}\text { Thickness } \\
\text { (m) }\end{array}$ & $\begin{array}{c}\text { Density } \\
\left(\mathrm{kg}^{\left.-\mathrm{m}^{-3}\right)}\right.\end{array}$ & $\begin{array}{c}\text { Bulk modulus } \\
(\mathrm{GPa})\end{array}$ & $\begin{array}{c}\text { Shear modulus } \\
(\mathrm{GPa})\end{array}$ & $\begin{array}{c}\text { Cohesion } \\
(\mathrm{MPa})\end{array}$ & $\begin{array}{c}\text { Friction angle } \\
\left({ }^{\circ}\right)\end{array}$ & $\begin{array}{c}\text { Tensile strength } \\
(\mathrm{MPa})\end{array}$ \\
\hline Conglomerate & 39 & 2950 & 20.94 & 18.03 & 12.21 & 41 & 10.63 \\
\hline $\begin{array}{l}\text { Fine } \\
\text { sandstone }\end{array}$ & 2 & 2900 & 9.27 & 8.84 & 7.59 & 31 & 6.72 \\
\hline Conglomerate & 3 & 2950 & 20.94 & 18.03 & 12.21 & 41 & 10.63 \\
\hline $\begin{array}{l}\text { Fine } \\
\text { sandstone }\end{array}$ & 2 & 2900 & 9.27 & 8.84 & 7.59 & 31 & 6.72 \\
\hline Siltstone & 2 & 2734 & 12.95 & 10.12 & 9.06 & 30 & 8.74 \\
\hline Mudstone & 2 & 2486 & 6.17 & 5.54 & 4.52 & 22 & 4.34 \\
\hline $\begin{array}{l}\text { Fine } \\
\text { sandstone }\end{array}$ & 1 & 2900 & 9.27 & 8.84 & 7.59 & 31 & 6.72 \\
\hline Mudstone & 24 & 2486 & 6.17 & 5.54 & 4.52 & 22 & 4.34 \\
\hline Coal seam & 5 & 1440 & 4.67 & 4.47 & 4.40 & 26 & 4.06 \\
\hline Siltstone & 10 & 2734 & 12.95 & 10.12 & 9.06 & 30 & 8.74 \\
\hline
\end{tabular}

\section{Discussions}

According to the displacement and mining-induced stress variation in the extra-thick roof, the following areas should be discussed in greater detail to analyze the dynamic evolution characteristics of deformation and movement of the extra-thick roof.

The extraction of a longwall mining face induced mininginduced changes and extra-thick roof movement above the mining face. The movement and failure processes of an extra-thick roof could be divided into three main periods: the undisturbed, movement stabilization, and sudden collapse periods. Because the mining face advancement distance in the physical experiment was short, the extra-thick roof deformation caused by bending and sinking was relatively small. The mining-induced stress of typical stress sensors was small; therefore, this stage could be categorized as belonging to the undisturbed period. With mining face advancement, the suspended roof length gradually increased and the roof bent and sank under the action of gravity. The bending moment and shearing force at both roof ends gradually increased, leading to roof failure. In addition, the horizontal stress was applied to the left and right boundaries of the physical model and the extra-thick roof collapsed slowly under the action of horizontal pressure. Therefore, this stage was part of the movement stabilization period. Because the main roof was composed of an extra-thick conglomerate, it could sustain a large stress level. Although the roof movement was dynamic in coal mining, an extra-thick roof was not disturbed until the roof reached a certain degree of deformation. The UCS of the extra-thick roof was $45 \mathrm{MPa}$, and its failure could occur only when the effect of the roof subsidence increased the extra-thick roof stress to the ultimate strength. It broke and caused roof caving in a large area and could easily induce coal bursts. This stage corresponded to the sudden collapse period. 


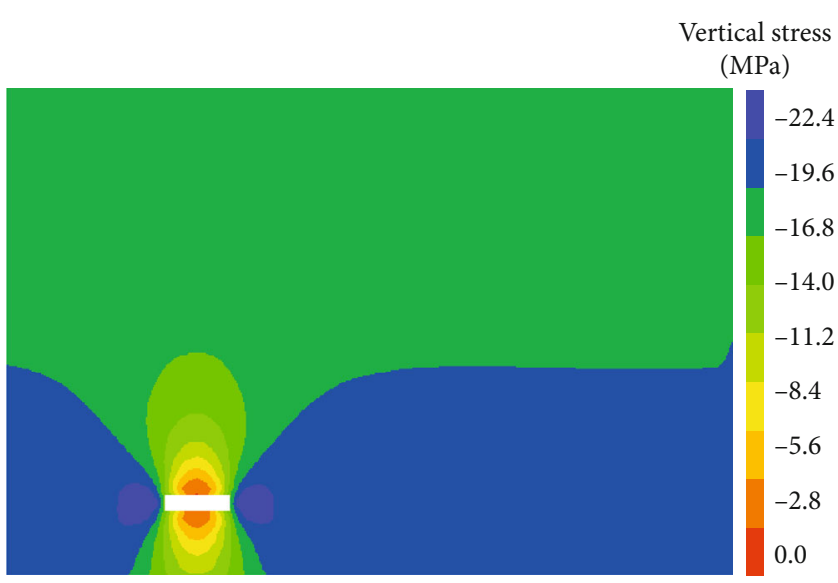

(a) Mining distance: $20 \mathrm{~cm}$

Vertical stress (MPa)

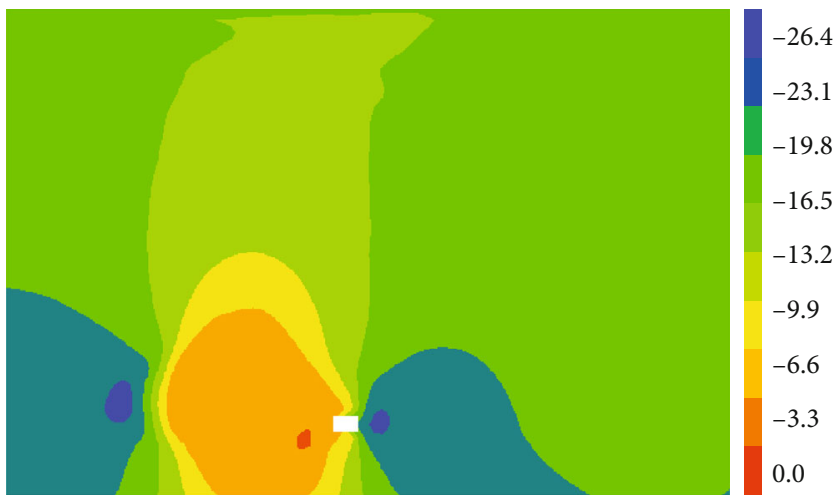

(c) Mining distance: $55 \mathrm{~cm}$

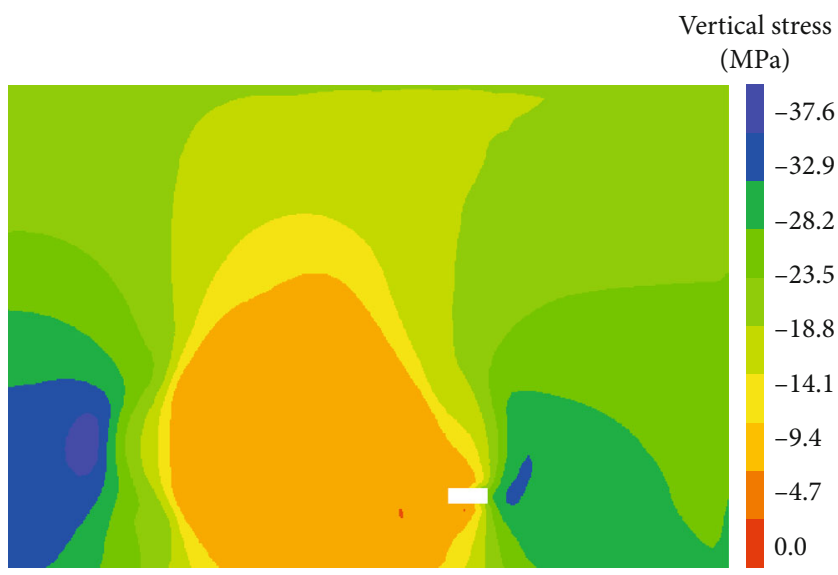

(e) Mining distance: $90 \mathrm{~cm}$

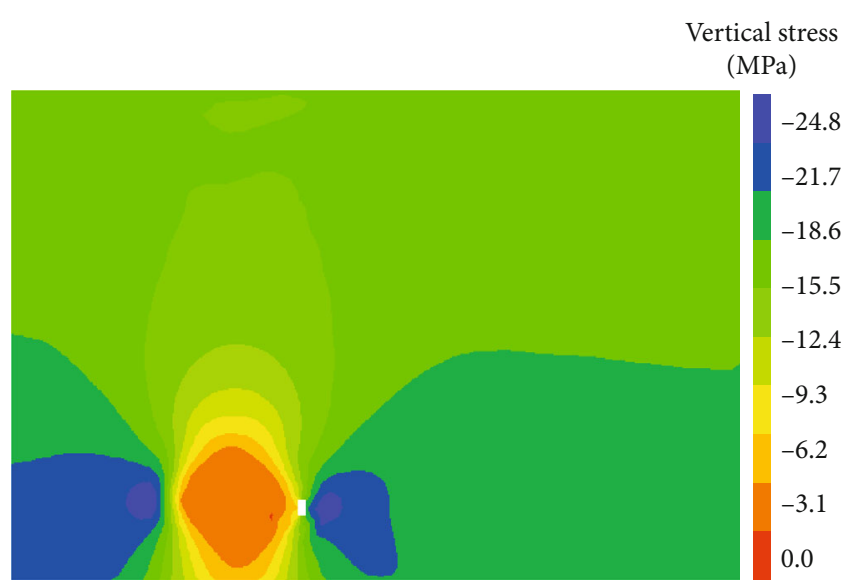

(b) Mining distance: $40 \mathrm{~cm}$

Vertical stress (MPa)

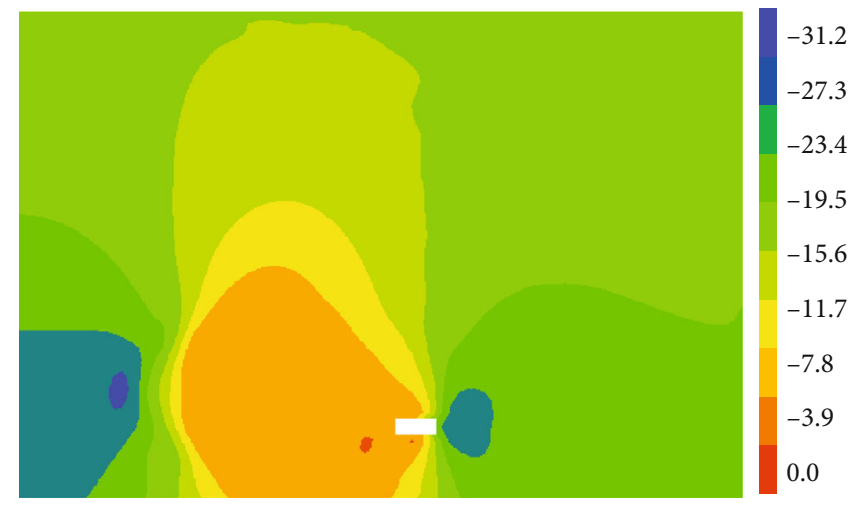

(d) Mining distance: $70 \mathrm{~cm}$

Vertical stress (MPa)

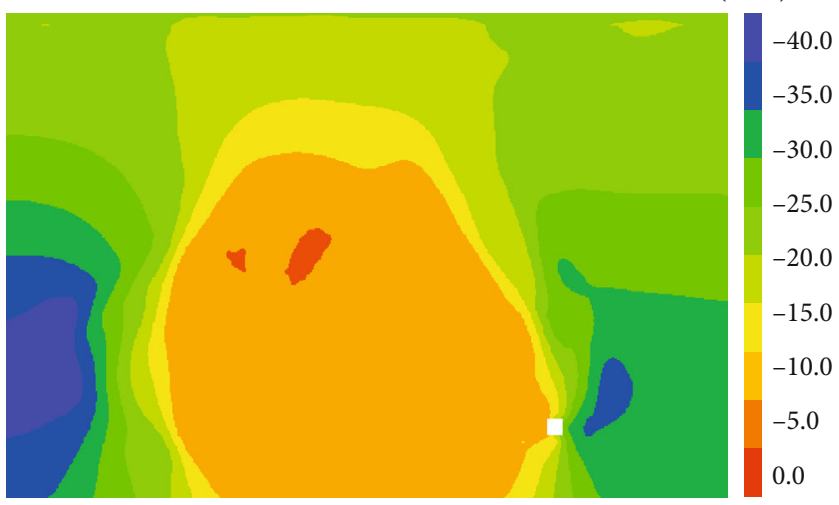

(f) Mining distance: $110 \mathrm{~cm}$

FIGURE 12: Vertical stress distribution of the extra-thick roof during the advancement of the mining face.

Throughout the mining process, the roof experienced five periodic caving. The displacement and velocity vector of the extra-thick roof increased sharply in this periodic caving, and the collapse height instantly expanded into the entire extrathick roof. Figures 6 and 9 showed that the results of the displacement and collapse state of the roof in the 3DEC model generally agreed with those in the physical experiment. When the stress monitoring points located on the extra- thick conglomerate were far away from the mining face outside the influence area of the mining disturbance, their stress remained in situ stress. With mining face advancement, the stress gradually increased and extensive deformation energy accumulated by degrees in the extra-thick conglomerates. When the extra-thick conglomerate reached its own ultimate strength, the roof caved for the fifth time and the extra-thick conglomerate stress changed abruptly. Meanwhile, the 


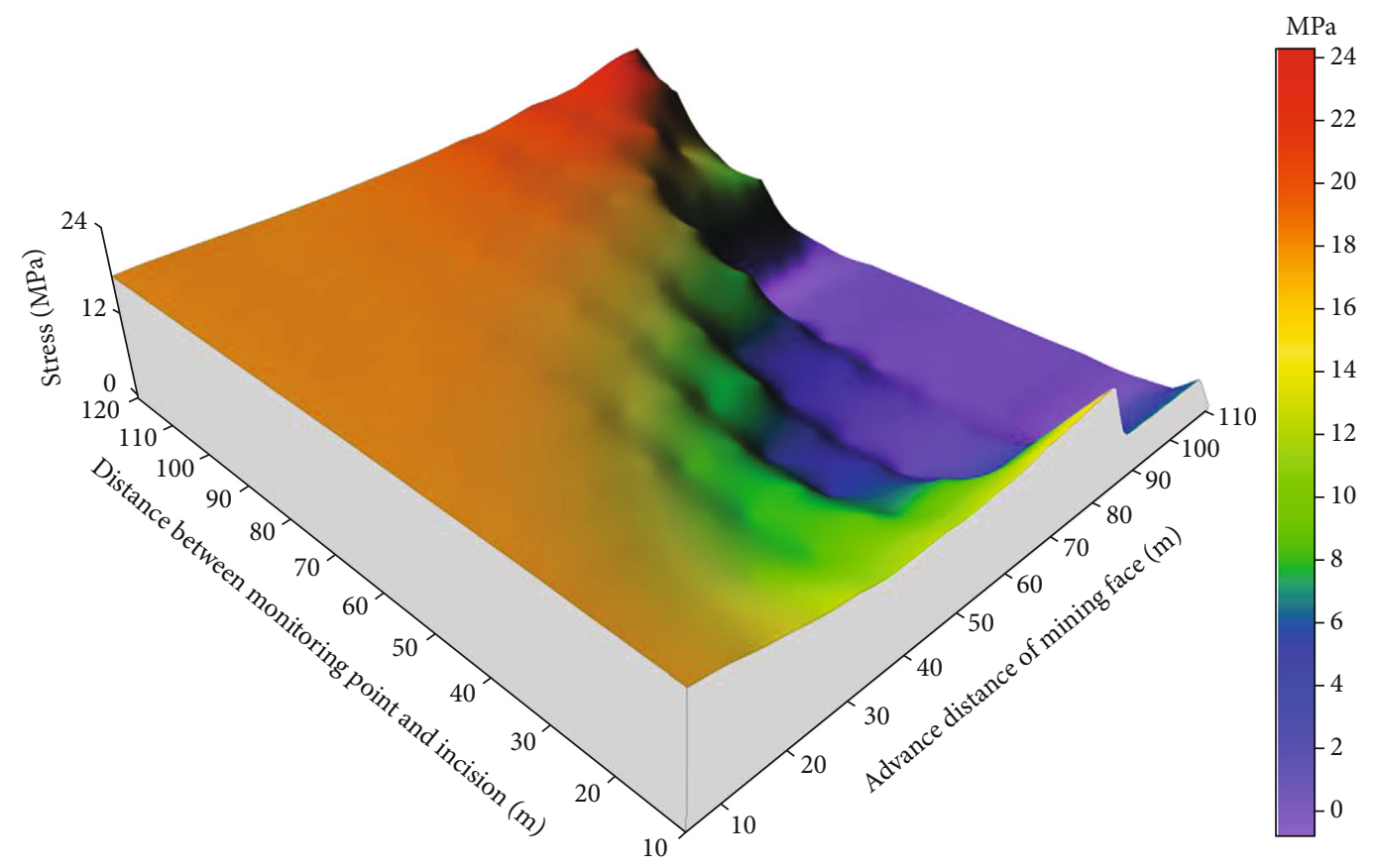

FIGURE 13: Vertical stress of the extra-thick conglomerate.

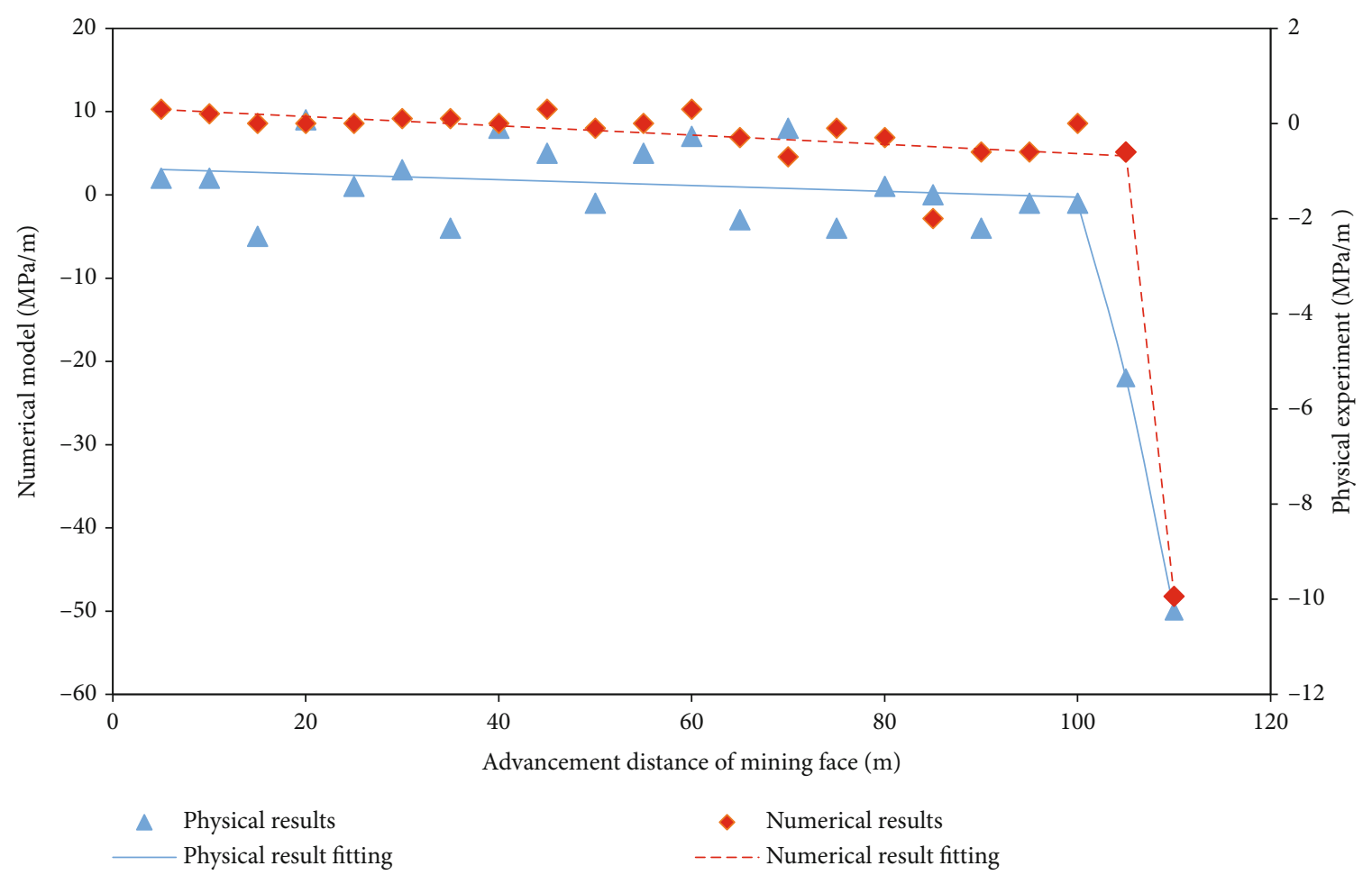

FIGURE 14: The stress comparison between numerical simulation and physical experiment.

mining-induced stress was characterized by a sudden decrease in the gradually increasing trend when the extrathick roof suddenly collapsed, as shown in Figures 7 and 13. The stress change characteristics of the \#8 measuring point at the same position in both the physical experiment and FLAC ${ }^{3 \mathrm{D}}$ model were basically synchronous, as shown in Figure 14.
Hence, the deformation and fracture of the extra-thick roof could lead to the continuous and unstable subsidence pressure exerted on the mining face and roadway, which provided a continuous force to the immediate roof, and coal seam and could cause a sudden decrease in the mininginduced stress of the extra-thick roof. This significantly contributed to the occurrence of coal bursts. 


\section{Conclusions}

Numerical simulations and physical experiments were conducted to study the movement and fracture characteristics of the extra-thick roof during coal seam mining. The detailed conclusions are as follows.

(1) The movement and failure processes of the extrathick roof could be divided into three main periods: the undisturbed, movement stabilization, and sudden collapse periods. The roof displacement essentially did not change during the undisturbed period. During the movement stabilization period, the displacement gradually increased into the upper roof and could be observed only in the immediate roof and the extra-thick roof was not disturbed by the mining activities. However, the displacement expanded rapidly into the extra-thick main roof during the sudden collapse period

(2) Although roof movement is a dynamic process during coal seam mining, the extra-thick main roof was undisturbed until the immediate roof experienced the fourth periodic caving. The UCS of the extrathick main roof was $45 \mathrm{MPa}$, and its failure could occur only when the effect of the roof subsidence increased the extra-thick main roof stress to the ultimate strength. Therefore, the strain energy was violently released when it accumulated in the extrathick roof failure process

(3) The extra-thick main roof collapse was only observed once in the physical experiment when a periodic roof caving occurred in the immediate roof. The displacement and velocity vector of the extra-thick main roof increased sharply in this periodic caving, and the collapse height instantly expanded into the extra-thick main roof. Meanwhile, the mining-induced stress was characterized by a sudden decrease in the gradually increasing trend when the extra-thick main roof suddenly collapsed

(4) As the mining face advanced, the movement and fracture of the extra-thick roof led to a continuous and unstable subsidence pressure exerted on the mining face and roadway. This pressure exertion provided a continuous force to the immediate roof and coal seam. This significantly contributed to the occurrence of coal bursts

\section{Data Availability}

All the original data used to support the findings of this study are available from the corresponding author upon request.

\section{Conflicts of Interest}

The authors declare that they have no conflicts of interest.

\section{Acknowledgments}

This research benefited from the support of the following funds from the Beijing Natural Science Foundation (8202041), National Natural Science Foundation of China (41872205), Yue Qi Young Scholar Project, China University of Mining \&Technology, Beijing (2018QN13), the Fundamental Research Funds for the Central Universities (2021YJSLJ10), and the State Key Research Development Program of China (2017YFC0603002 and 2016YFC0801401).

\section{References}

[1] Y. D. Jiang, Y. S. Pan, F. X. Jiang, L. M. Dou, and Y. Ju, "State of the art review on mechanism and prevention of coal bumps in China," Journal of China Coal Society, vol. 39, no. 2, pp. 205213, 2014.

[2] L. Yuan, Y. D. Jiang, X. Q. He et al., "Research progress of precise risk accurate identification and monitoring early warning on typical dynamic disasters in coal mine," Journal of China Coal Society, vol. 43, no. 2, pp. 306-318, 2018.

[3] Y. D. Jiang and Y. X. Zhao, "State of the art: investigation on mechanism, forecast and control of coal bumps in China," Chinese Journal of Rock Mechanics and Engineering, vol. 34, no. 11, pp. 2188-2204, 2015.

[4] H. W. Wang, R. M. Shi, D. X. Deng, Y. D. Jiang, G. Wang, and W. L. Gong, "Characteristic of stress evolution on fault surface and coal bursts mechanism during the extraction of longwall face in Yima mining area, China," Journal of Structural Geology, vol. 136, p. 104071, 2020.

[5] H. W. Wang, S. Xue, R. M. Shi, Y. D. Jiang, W. L. Gong, and L. T. Mao, "Investigation of fault displacement evolution during extraction in longwall panel in an underground coal mine," Rock Mechanics and Rock Engineering, vol. 53, no. 4, pp. 18091826, 2020.

[6] L. R. Alejano, J. Taboada, F. García-Bastante, and P. Rodriguez, "Multi-approach back-analysis of a roof bed collapse in a mining room excavated in stratified rock," International Journal of Rock Mechanics and Mining Sciences, vol. 45, no. 6, pp. 899-913, 2008.

[7] M. Tsesarsky, "Deformation mechanisms and stability analysis of undermined sedimentary rocks in the shallow subsurface," Engineering Geology, vol. 133-134, pp. 16-29, 2012.

[8] F. Q. Gao, D. Stead, H. P. Kang, and Y. Z. Wu, "Discrete element modelling of deformation and damage of a roadway driven along an unstable goaf - a case study," International Journal of Coal Geology, vol. 127, pp. 100-110, 2014.

[9] M. Shabanimashcool and C. C. Li, "Analytical approaches for studying the stability of laminated roof strata," International Journal of Rock Mechanics and Mining Sciences, vol. 79, pp. 99-108, 2015.

[10] R. Gao, J. X. Yang, T. J. Kuang, and H. J. Liu, "Investigation on the ground pressure induced by hard roof fracturing at different layers during extra thick coal seam mining," Geofluids, vol. 2020, Article ID 8834235, 15 pages, 2020.

[11] T. Zhao, C. Y. Liu, K. Yetilmezsoy, B. S. Zhang, and S. Zhang, "Fractural structure of thick hard roof stratum using long beam theory and numerical modeling," Environment and Earth Science, vol. 76, 2017. 
[12] J. G. Ning, J. Wang, L. S. Jiang, N. Jiang, X. S. Liu, and J. Q. Jiang, "Fracture analysis of double-layer hard and thick roof and the controlling effect on strata behavior: a case study," Engineering Failure Analysis, vol. 81, pp. 117-134, 2017.

[13] W. L. Shen, J. B. Bai, X. Y. Wang, and Y. Yu, "Response and control technology for entry loaded by mining abutment stress of a thick hard roof," International Journal of Rock Mechanics and Mining Sciences, vol. 90, pp. 26-34, 2016.

[14] G. S. P. Singh and U. K. Singh, "Numerical modeling study of the effect of some critical parameters on caving behavior of strata and support performance in a longwall working," Rock Mechanics and Rock Engineering, vol. 43, no. 4, pp. 475-489, 2010.

[15] N. Zhou, J. X. Zhang, H. Yan, M. Li, and M. Wang, "Deformation behavior of hard roofs in solid backfill coal mining using physical models," Energies, vol. 10, no. 4, 2017.

[16] W. Wang, Y. P. Cheng, H. F. Wang, W. Li, and L. Wang, "Coupled disaster-causing mechanisms of strata pressure behavior and abnormal gas emissions in underground coal extraction," Environmental Earth Sciences, vol. 74, no. 9, pp. 6717-6735, 2015.

[17] Q. S. Bai, S. H. Tu, F. T. Wang, and C. Zhang, "Field and numerical investigations of gateroad system failure induced by hard roofs in a longwall top coal caving face," International Journal of Coal Geology, vol. 173, pp. 176-199, 2017.

[18] J. L. Jia, L. W. Cao, D. J. Zhang, X. W. Chai, S. Q. Liu, and L. Han, "Study on the fracture characteristics of thick-hard limestone roof and its controlling technique," Environmental Earth Sciences, vol. 76, no. 17, 2017.

[19] H. W. Wang, Y. D. Jiang, S. Xue et al., "Influence of fault slip on mining-induced pressure and optimization of roadway support design in fault-influenced zone," Journal of Rock Mechanics and Geotechnical Engineering, vol. 8, no. 5, pp. 660-671, 2016.

[20] P. Wang, L. S. Jiang, J. Q. Jiang, P. Q. Zheng, and W. Li, "trata behaviors and rock burst-inducing mechanism under the coupling effect of a hard, thick stratum and a normal fault," International Journal of Geomechanics, vol. 18, no. 2, pp. 15321546, 2018.

[21] Z. B. Cheng, D. Z. Kong, and J. H. Yang, "The breaking characteristics of thick hard roof and determination of support capacity in fully mechanized caving face," Journal of Mining Science and Technology, vol. 1, no. 2, pp. 172-180, 2016.

[22] W. L. Gong, Y. Y. Peng, M. C. He, and J. Wang, "Thermal image and spectral characterization of roadway failure process in geologically $45^{\circ}$ inclined rocks," Tunnelling and Underground Space Technology, vol. 49, pp. 156-173, 2015.

[23] S. Renliang, H. Bo, S. Yongwei, W. Huimin, and F. Xiaolin, "Ground pressure features of roadway under close range goaf in the Xinyu mine," Journal of Mining Science and Technology, vol. 1, no. 1, pp. 29-37, 2016.

[24] M. Amini, H. Sarfaraz, and K. Esmaeili, "Stability analysis of slopes with a potential of slide-head-toppling failure," International Journal of Rock Mechanics and Mining Sciences, vol. 112, pp. 108-121, 2018.

[25] M. Z. Li, Z. M. Ma, D. L. Xue, and Y. H. Fan, "Research of cumulative energy blasting technology with deep and shallow hole combined in hard roof," Journal of Mining Science and Technology, vol. 5, no. 6, pp. 616-623, 2020.

[26] R. Kumar, A. K. Singh, A. K. Mishra, and R. Singh, "Underground mining of thick coal seams," International Journal of
Mining Science and Technology, vol. 25, no. 6, pp. 885-896, 2015.

[27] H. R. Chen, S. Q. Qin, L. Xue, B. C. Yang, and K. Zhang, “A physical model predicting instability of rock slopes with locked segments along a potential slip surface," Engineering Geology, vol. 242, pp. 34-43, 2018.

[28] B. Ghabraie, G. Ren, and J. V. Smith, "Characterising the multi-seam subsidence due to varying mining configuration, insights from physical modelling," International Journal of Rock Mechanics and Mining Sciences, vol. 93, pp. 269-279, 2017.

[29] Y. K. Liu, F. B. Zhou, L. Liu, C. Liu, and S. Y. Hu, “An experimental and numerical investigation on the deformation of overlying coal seams above double-seam extraction for controlling coal mine methane emissions," International Journal of Coal Geology, vol. 87, no. 2, pp. 139-149, 2011.

[30] H. W. Wang, R. M. Shi, J. Q. Song, Z. Tian, D. X. Deng, and Y. D. Jiang, "Mechanical model for the calculation of stress distribution on fault surface during the underground coal seam mining," International Journal of Rock Mechanics and Mining Sciences, vol. 144, p. 104765, 2021.

[31] H. W. Wang, R. M. Shi, C. S. Lu, Y. D. Jiang, D. X. Deng, and D. Q. Zhang, "Investigation of sudden faults instability induced by coal mining," Safety Science, vol. 115, pp. 256-264, 2019.

[32] W. L. Gong, J. Wang, and D. Q. Liu, Infrared Thermography for Geomechanical Model Test, Science Press, Beijing, 2016.

[33] B. Ghabraie, G. Ren, X. Y. Zhang, and J. Smith, "Physical modelling of subsidence from sequential extraction of partially overlapping longwall panels and study of substrata movement characteristics," International Journal of Coal Geology, vol. 140, pp. 71-83, 2015.

[34] W. S. Zhu, Y. Li, S. C. Li, S. G. Wang, and Q. B. Zhang, "Quasithree-dimensional physical model tests on a cavern complex under high in-situ stresses," International Journal of Rock Mechanics and Mining Sciences, vol. 48, no. 2, pp. 199-209, 2010.

[35] M. C. He, X. N. Jia, W. L. Gong, and L. Faramarzi, "Physical modeling of an underground roadway excavation in vertically stratified rock using infrared thermography," International Journal of Rock Mechanics and Mining Sciences, vol. 47, no. 7, pp. 1212-1221, 2010.

[36] X. M. Sun, F. Chen, C. Y. Miao et al., "Physical modeling of deformation failure mechanism of surrounding rocks for the deep-buried tunnel in soft rock strata during the excavation," Tunnelling and Underground Space Technology, vol. 74, pp. 247-261, 2018.

[37] L. T. Mao, X. X. Zhu, L. Q. An, G. S. Cai, and N. Hao, “Application of digital target marker image correlation method in model experiment," Journal of Liaoning Technical University (Natural Science), vol. 32, no. 10, pp. 1367-1373, 2013.

[38] L. T. Mao, N. Hao, L. Q. An, F. P. Chiang, and H. B. Liu, “3D mapping of carbon dioxide-induced strain in coal using digital volumetric speckle photography technique and X-ray computer tomography," International Journal of Coal Geology, vol. 147-148, pp. 115-125, 2015.

[39] Z. Chen, Z. Z. Zhang, L. N. Wang, H. Wang, and S. S. Zhang, "Study on water absorption and pore structure fractal characteristics of slag-based geopolymer," Journal of Mining Science and Technology, vol. 6, no. 2, pp. 204-209, 2021.

[40] Q. Lin and J. F. Labuz, "Fracture of sandstone characterized by digital image correlation," International Journal of Rock Mechanics and Mining Sciences, vol. 60, pp. 235-245, 2013. 
[41] H. Munoz, A. Taheri, and E. K. Chanda, "Pre-Peak and postpeak rock strain characteristics during uniaxial compression by 3D digital image correlation," Rock Mechanics and Rock Engineering, vol. 49, no. 7, pp. 2541-2554, 2016.

[42] A. Fakhimi, Q. Lin, and J. F. Labuz, "Insights on rock fracture from digital imaging and numerical modeling," International Journal of Rock Mechanics and Mining Sciences, vol. 107, pp. 201-207, 2018.

[43] J. H. Zhao, L. M. Yin, and W. J. Guo, "Stress-seepage coupling of cataclastic rock masses based on digital image technologies," Rock Mechanics and Rock Engineering, vol. 51, no. 8, pp. 23552372, 2018. 